\title{
Early Adverse Experiences and the Developing Brain
}

\author{
Johanna Bick ${ }^{1,2}$ and Charles A Nelson ${ }^{\star, 1,2,3}$ \\ ${ }^{1}$ Department of Pediatrics, Boston Children's Hospital, Boston, MA, USA; ${ }^{2}$ Harvard Medical School, Boston, MA, USA; \\ ${ }^{3}$ Harvard Graduate School of Education, Boston, MA, USA
}

\begin{abstract}
Children exposed to various forms of adversity early in life are at increased risk for a broad range of developmental difficulties, affecting both cognitive and emotional adjustment. We review a growing body of evidence suggesting that exposure to adverse circumstances affects the developing brain in ways that increase risk for a myriad of problems. We focus on two forms of adversity, one in which children are exposed to childhood maltreatment in family environments, and another in which children are exposed to extreme psychosocial deprivation in contexts of institutional rearing. We discuss ways in which each of these experiences represent violations of species-expected caregiving conditions, thereby imposing challenges to the developing brain. We also review emerging data pointing to the effectiveness of early intervention in remediating neurodevelopmental consequences associated with maltreatment or institutional rearing. We conclude by discussing implications of this work for public health efforts and highlight important directions for the field.
\end{abstract}

Neuropsychopharmacology Reviews (2016) 41, 177-196; doi: 10.1038/npp.2015.252; published online 28 October 2015

\section{INTRODUCTION}

It is well established that early adverse experiences increase risk for maladaptive outcomes, with sequelae spanning a broad number of developmental domains. In the cognitive realm, children are at increased risk for memory problems, learning difficulties, and cognitive delays, which are likely contributors to disproportionately higher rates of academic difficulties and school adjustment issues (Anda et al, 2006; Nelson et al, 2007; Cohen et al, 2008; Bos et al, 2009; De Bellis et al, 2009; Loman et al, 2009; Johnson et al, 2010; Pollak et al, 2010; van den Dries et al, 2010; Pechtel and Pizzagalli, 2011). Attention and behavior regulatory difficulties are also highly prevalent in children exposed to early adversity, likely underpinning risk for ADHD and associated behavioral problems (Bos et al, 2009; Pollak et al, 2010; Colvert et al, 2008a; Ouyang et al, 2008). Atypical emotional development is also often observed in children reared in adverse contexts. Problems involve difficulties with stress, sensitivity to reward, and emotion and behavioral regulation, which lead to increased rates of psychiatric disorders, interpersonal problems, and engagement in high-risk antisocial activities (Pollak et al, 2000; Pollak and Kistler, 2002; Pollak and Sinha, 2002; Pollak and Tolley-Schell, 2003; Fries and Pollak, 2004; Cicchetti and

${ }^{*}$ Correspondence: $\operatorname{Dr}$ CA Nelson, Department of Pediatrics, Boston Children's Hospital, 1 Autumn Street, Boston, MA 02115, USA, Tel: +1 617 355 0401, Fax: +1 6177300518 ,

E-mail: Charles.Nelson@childrens.harvard.edu

Received 18 April 2015; revised 12 August 2015; accepted 14 August 2015; accepted article preview online 3 September 2015
Curtis, 2005; Colvert et al, 2008b; Lyons-Ruth, 2008; Dillon et al, 2009; Zeanah et al, 2009).

The sheer number of adverse consequences associated with early-life stressors reinforces the notion that this is a large public health concern, both for individuals and larger society. Accordingly, there is a large impetus to understand how and why these early adverse experiences so strongly impact development. Driven by this overarching question, there are growing efforts to understand how basic neurobiology may be shaped by these experiences and increase risk for ongoing difficulties.

In this review, we summarize current understanding of the extent to which early adverse experiences shape the developing brain. We first review basic principles of normative brain development in order to provide a context for understanding and identifying potential alterations among children reared in adverse circumstances. Next, we review the accumulating body of evidence indicating that early adverse rearing experiences alter the course of brain development. We subdivide our review into experiences involving childhood maltreatment within family settings and experiences involving exposure to extreme neglect in institutional centers. For both of these early adverse experiences, we discuss a smaller body of work demonstrating how early intervention supports normalization in these neurobiological systems, potentially buffering children against risk for subsequent problems. We conclude our review by summarizing current understanding in the field, highlighting unresolved questions, and suggesting directions for future work. 


\section{EARLY EXPERIENCE AND BRAIN DEVELOPMENT}

In this section, we review several basic principles of brain development in order to provide a context for understanding patterns of atypical neurodevelopment among children reared in adverse settings. For a more in depth review, see Nelson and Jeste (2009).

\section{Human Brain Development is a Protracted Process}

The human brain follows a protracted course of development, beginning approximately 2 weeks after conception and reaching adult maturity in the third decade of life. Postnatal development is marked by an overproduction of synapses, which occurs largely under genetic control. This overabundance of synapses, reflecting an overproduction of dendrites, dendritic spines, and axons during the perinatal period (Huttenlocher et al, 1982; LaMantia and Rakic, 1994; Petanjek et al, 2008), is followed by pruning of the uncommitted synapses. Pruning is influenced by experience, thus allowing brain networks to develop, fine-tune, and become more organized and efficient. It also allows for the brain to optimize in a way that supports its maximal adaptation to the surrounding environment.

Brain regions vary in the time point at which peak synaptogenesis is reached. As demonstrated in human and non-human primate work, more basic structures, such as the visual cortex, reach peak synaptogenesis within the first 8 months of life, however, more complex structures in the prefrontal cortex reach their peak around the 15th postnatal month (Bourgeois et al, 1994; Huttenlocher and Dabholkar, 1997). Regions also vary in their respective onset of experience-based pruning. These timing differences affect the extent to which regions remain sensitive to environmental input; regions with later periods of peak synaptogenesis undergo experience-based pruning at a later point of development.

The final stage of brain development involves myelination, during which certain axons are wrapped in a fatty sheaf (myelin). As myelinated axons transmit signals faster than unmyelinated axons, this process supports increased neuronal conduction, speed, and communication. The process of myelination begins in the end of the second trimester, increases linearly across the first two decades of life, and then continues more slowly into middle adulthood. Brain regions also vary in their timing of myelination. For more basic structures, such as those involved in sensory processing, myelination is typically complete by the preschool years. In contrast, the prefrontal cortex does not become fully myelinated until adolescence or early adulthood (Yakovlev and Lecours, 1967; Brody et al, 1987; Benes et al, 1994). This is also true for some regions of the hippocampus (see Jabes and Nelson, 2015, ahead of print).

\section{Brain Development is Shaped by Genetics and Experience}

Genetic processes predominate during much of the prenatal period (although environmental influences, such as exposure to maternal stress hormones, teratogens, nutritional deficiencies, or illness, critically shape prenatal brain development; Morgane et al, 1993; Thompson et al, 2009; Boksa, 2010). In comparison, postnatal phases of brain development rely heavily on experience. Although genes provide a general 'blueprint' for brain development, with each individual holding a unique genetic plan, the environment determines the extent to which this blueprint is carried out. Implicit here is that variations at the genomic level will influence how signals from the environment are utilized; and further variations in the environment, and associated input provided to the brain, will affect patterns of gene expression that guide neural development.

\section{There are Sensitive Periods of Brain Development}

Adding to this complexity, the timing of environmental input also heavily shapes the brain's potential for normative development. For the brain to reach maturity, it is assumed that certain signals from the environment will be available at certain points in development. This process is often referred to as 'experience-expectant' development. As with other processes, sensitive periods for more basic circuitry occur earlier than for circuitry that is more complex (Fox et al, 2010).

The existence of these sensitive periods is considered evolutionarily advantageous for a number of reasons. First, it is more efficient for the brain to capitalize on widely available signals from the environment as a means for guiding development, rather than exclusively relying on genetic signaling alone. Second, it is highly adaptive for humans to tailor neurobiology to their surrounding environments. In fact, this adaptability and optimization toward ones surroundings is considered a primary driver of the survival and proliferation of the human species (Magill et al, 2013).

\section{The Brain Develops in a Hierarchical Manner}

As discussed above, development of the brain starts with the most basic systems (brainstem, sensory motor regions) and ends with the most complex (prefrontal cortex). Moreover, the foundation of later developing, more advanced circuitry depends on experienced-based development of more basic processes and circuitries. For example, exposure to a range of sounds supports the development of neural circuitry underlying auditory perception (including speech perception), which is necessary for the development of higher order processes including speech and language comprehension (Greenough et al, 1987). Accordingly, the formation of more basic neural circuitry via certain early experiences gives rise to the more advanced circuitry and functions later on in life. 
To summarize, the human brain has evolved to develop within a certain set of parameters. Maturity comes about via genetic and environmental factors and their complex interactions over time. The absence of expected input during sensitive periods of brain development, therefore, threatens the brain's ability to reach its genetic potential. In this review, we focus on how early adverse rearing conditions represent violations in expected caregiving input, and review current evidence supporting their impact on brain development.

\section{EARLY ADVERSE REARING EXPERIENCES AND BRAIN DEVELOPMENT}

There are many ways in which children can be exposed to adverse circumstances early in life. Here, we focus a specific form of early adversity involving compromises in the parent-child relationship. Our goal is to review evidence showing that atypical exposure to these critical early caregiving experiences affects the developing brain, and increases risk for problematic outcomes.

Given the altricial nature of the human species, access to responsive and stable caregivers during childhood is considered necessary for normative brain development (Tottenham et al, 2014; Greenough et al, 1987). Starting at birth, caregivers provide protection and safety, and without them, there is virtually no chance for offspring survival. Beyond basic protection, caregivers provide contingent input that supports ongoing brain and behavioral development. For example, caregivers respond to distress, which supports eventual development of self-regulatory capabilities and the neurobiological systems that subserve them. Caregivers also offer normative cognitive, social, and emotional input. This drives the development of higher-level social-emotional and cognitive development and supports the development of neural circuitry that underpins these domains. In the context of these early caregiving relationships, children also fulfill a key developmental task, which is to form a selective attachment to a primary caregiver. Accordingly, access to stable and responsive caregiving is a key aspect of the caregiving environment that drives normative brain and behavioral development.

When children are reared outside these normative caregiving conditions, the potential for normative development becomes compromised. In this review, we focus on two ways in which children can experience species-atypical caregiving, with the first form experienced in maltreating family settings, and the second form experienced during institutional rearing. We review extant evidence indicating how these adverse conditions affect the developing brain. We also highlight emerging evidence suggesting the potential for early intervention to support normalization in specific neural systems. Our focus is on how these early adverse rearing conditions affect the developing brain. Therefore, we limit our review to studies examining brain development in childhood and adolescence.

\section{MALTREATMENT IN FAMILY SETTINGS}

Children reared in maltreating family environments face species-atypical rearing experiences at a point in development when the brain is highly sensitive to caregiving input. Often defined categorically, involving physical, emotional, or sexual abuse, or physical or emotional neglect, childhood maltreatment represents an absence of speciesexpected access to stable and responsive caregiving.

In conditions involving physical, emotional, or sexual abuse, children are exposed to high levels of threatening input, which may involve physical or emotional harm. In contrast, conditions of physical or emotional neglect involve an absence of experiences necessary for supporting physical or emotional development. Experiences of abuse and neglect often co-occur (Green et al, 2010), making it difficult to study the relative contribution of each form of maltreatment on development. However, interest in disentangling the discrete challenges confronted in these broader categorical definitions of maltreatment has grown in recent years (McLaughlin et al, 2014).

In addition to the absence of responsive caregiving in families of origin, maltreated children can also face caregiver instability at a formative point in development. This can occur when children experience caregiving transitions, such as if placed into foster homes after being removed from their biological families. The obvious intent of the separations is to remove children from harm, and offer a stable, supportive environment allowing children to thrive. However, in some cases, children transition between multiple placements before a final placement decision is made. When these excessive caregiver transitions occur during a formative point in development, such as during the first years of life, the potential for normative social development, and relevant neurobiological underpinnings can be compromised.

\section{Consequences of Maltreatment on Brain Structure}

The consequences of maltreatment on the structural properties of brain development have been examined in a number of studies. While some of these investigations have elucidated global changes in brain development, others have revealed changes in circuitries that support higher-level emotional and cognitive functioning.

Global volumetric changes. Across several studies, childhood maltreatment exposure has been associated with global changes in brain structure. For example, relative to nonmaltreated children, maltreated children with and without trauma-related psychiatric disorders, such as posttraumatic stress disorder (PTSD), have shown reduced brain volumes, with alterations observed in temporal, frontal, parietal, and occipital regions, and in overall cortical gray and white matter volume (De Bellis et al, 1999, 2002; Carrion et al, 2001; Hanson et al, 2010; De Brito et al, 2013). There is some evidence in studies involving youth with PTSD secondary to maltreatment that the timing and chronicity of the abuse 
is associated with the magnitude of the change; specifically, early age of onset and longer duration of childhood maltreatment has predicted greater reductions in brain volumes (De Bellis et al, 2002).

Limbic circuitry. Given its involvement in emotion processing, stress regulation, and learning and memory (Phelps, 2004; Murray, 2007), there has been substantial effort to understand the impact of childhood maltreatment on limbic circuitry. Informed from animal work (Lupien et al, 2009), research has focused on the development of two key limbic structures, the amygdala and the hippocampus.

Relative to controls, differences in amygdala volumes have generally not been observed in children exposed to childhood maltreatment with PTSD (De Bellis et al, 1999, 2001; Woon and Hedges, 2008) or other psychiatric conditions (Hanson et al, 2010), or in children without maltreatment-induced psychiatric disorders (De Brito et al, 2013). However, two recent investigations showed smaller amygdala volumes in children exposed to abuse and neglect. The first examined adolescents and showed that retrospective reports of emotional neglect (but not other forms of maltreatment) were inversely associated with amygdala volumes (Edmiston et al, 2011). These findings suggest that the severity and type of the maltreatment can predict the extent of morphological change. The second examined pre-adolecent children and showed that physical abuse was associated with smaller amygdala volumes; these reductions further conferred risk for behavioral problems (Hanson et al, 2014).

Few studies have examined how maltreatment interferes with the normative growth in amygdala volumes over time. However, in one study, youth who retrospectively reported histories of maltreatment, who also exhibited current psychiatric problems, showed faster growth of the left amygdala from early to mid adolescence, relative to youth who reported maltreatment but did not have current psychiatric symptoms (Whittle et al, 2013). This indicates that maltreated children with and without secondary psychiatric disorders may vary in the extent to which the amygdala changes over time. It is not yet known whether these differences are a risk factor for, or a consequence of, the psychiatric disorder associated with the maltreatment exposure. Regardless, these data suggest that there may be important differences in neurodevelopment among maltreated children who go on to meet criteria for psychiatric disorders from those who do not.

Few studies have investigated associations between childhood maltreatment exposure and amygdala development using prospective, longitudinal designs. These designs offer an improvement over studies that rely on retrospective characterizations of maltreatment, where conclusions regarding causality are limited. In one study, infants exposed to maternal depression (a known risk factor for poor caregiving responsiveness) were followed over time. Results from MRI scans conducted once children reached late childhood showed a positive association between maternal depression severity and amygdala size (Lupien et al, 2011).
Relative to controls, changes in the hippocampus have not typically observed in children exposed to maltreatment with or without PTSD (De Bellis et al, 1999, 2002; Woon and Hedges, 2008; Carrion et al, 2009; De Brito et al, 2013), despite more robust evidence for smaller volumes in adults who report maltreatment (McCrory et al, 2011a; Hart and Rubia, 2012). Decreased hippocampal volumes have been observed in late childhood and adolescence in youth with maltreatment-related PTSD (Tupler and De Bellis, 2006; Carrion et al, 2007), depression (Rao et al, 2010b) and in maltreated youth without psychiatric disorders (Rao et al, 2010b; Edmiston et al, 2011; Hanson et al, 2014) relative to controls. In one study, the severity of retrospective reports of emotional neglect (but not other types of maltreatment) was inversely inversely associated with hippocampal volumes (Edmiston et al, 2011). In another investigation involving a large age range of children (from 4 to 17 years), PTSD secondary to maltreatment was associated with relative increases in white matter content in the hippocampus, with no corresponding changes in gray matter. Both the age of maltreatment onset and level of psychiatric symptomatology was associated with the magnitude of hippocampal change, suggesting that developmental timing and/or duration of the maltreatment and severity of psychiatric symptoms influences the extent to which these structures are affected (Tupler and De Bellis, 2006).

Few studies have examined changes in normative hippocampal development in maltreated children $v s$ controls. One study involving youth with PTSD secondary to maltreatment showed that hippocampal changes did not appear immediately following the maltreatment exposure, but emerged in the subsequent 12-18 months (Carrion et al, 2007). In another study, youth who retrospectively reported on childhood maltreatment, who also reported psychiatric symptoms, showed slower growth of the left hippocampus when compared with maltreated youth without current symptomatology (Whittle et al, 2013). As observed with amygdala changes, this suggests that the magnitude of change may become more pronounced over time, and that the presence or absence of psychopathology may influence the extent of the morphological change.

There are few prospective longitudinal studies on the impact of childhood maltreatment and hippocampal development. However, in a longitudinal study of preschool children with and without depression, maternal support received during early childhood was positively associated with hippocampal volumes in middle childhood; again, the presence or absence of a secondary psychiatric disorder also affected results; positive parenting had a stronger effect on hippocampal volumes in non-depressed children (Luby et al, 2012). These results conflict with those reported from another longitudinal study involving children who were prenatally exposed to cocaine. In this study, lower parenting quality in early childhood was associated with larger hippocampal volumes in early adolescence. Importantly, parenting quality, but not other factors of the environment, such as levels of general cognitive stimulation, predicted 
long-term hippocampal development (Rao et al, 2010b). Taking these studies together, evidence suggests that there may be critical interactive effects between prenatal risk factors and postnatal caregiving quality in shaping hippocampal growth.

Frontal regions. The prefrontal cortex has a relatively protracted course of development relative to other neural structures (Gogtay et al, 2006) making it highly sensitive to stress (Arnsten, 2009) such as that which occurs on contexts of childhood maltreatment. The development of this region aligns with emergence of complex emotional and cognitive functions, including attention, executive function, and self-regulatory abilities that also take place during childhood and adolescence (Fuster, 2001), which are often disrupted in maltreatment exposed children. Accordingly, there is substantial interest in understanding how maltreatment may interfere with developmental trajectories of this region.

Evidence supporting the impact of childhood maltreatment on the development of the prefrontal cortex varies across studies. Findings are especially mixed in studies involving maltreated youth who also meet criteria for PTSD in cross-sectional studies. In one study, no significant associations between maltreatment-related PTSD and total PFC volumes were observed (De Bellis et al, 1999). In another study, both smaller total PFC volumes and lower PFC white matter in maltreated youth with PTSD were observed, relative to controls (De Bellis et al, 2002). Some studies have examined maltreatment-associated alterations in separate PFC regions. In several studies, youth with PTSD secondary to maltreatment showed increased middle inferior and ventral regions (Richert et al, 2006; Carrion et al, 2009) and superior/dorsal regions (Carrion et al, 2009) relative to controls.

Increased sophistication in neuroimaging technologies and accompanying understanding in subregions of the frontal lobe have allowed for more detailed investigations of the influence of maltreatment on the PFC. Changes in $\mathrm{PFC}$ regions implicated in cognitive and emotional control have been observed in recent studies. For example, relative to controls, reductions in the orbitofrontal cortex, a region known for its role in reinforcement-based decision making and emotion regulation (Ochsner and Gross, 2005; Schoenbaum et al, 2007) have been reported in children exposed to physical maltreatment (Hanson et al, 2010) or maltreatment more generally (De Brito et al, 2013; Kelly et al, 2013); additional reductions have been observed in the superior frontal gyrus, a region known to support working memory (Kelly et al, 2013). Physical maltreatment exposure has also been associated with reductions in the dorsolateral prefrontal cortex (Hanson et al, 2010), a region implicated in working memory, cognitive regulation of emotion, and planning (Levy and Goldman-Rakic, 2000; Miller and Cohen, 2001; Ochsner et al, 2002). Higher levels of retrospectively reported physical abuse and emotional neglect were associated with greater decreases in the orbitofrontal cortex, the subgeneal cortex (a region also implicated in emotional control), and the dorsolateral prefrontal cortex in a study involving adolescents (Edmiston et al, 2011). This suggests that the type and severity of the exposure may have critical implications for the degree to which subregions of the prefrontal cortex are affected.

The anterior cingulate cortex (ACC), which is located in the medial frontal lobe, supports the interface between the frontal regions and limbic system. The ACC has been associated with various cognitive processes involving error detection, motivation, reward response, and decision making (Botvinick et al, 2004). Despite evidence showing consistent structural alterations in this region in investigations involving adults who report retrospectively on childhood maltreatment, morphological changes have not typically been observed in children exposed to maltreatment (Hart and Rubia, 2012); however, reduced thickness of the ACC has been observed in one study involving children with histories of maltreatment, which may reflect neurodevelopmental alterations in neuronal pruning and organization in this region (Kelly et al, 2013).

Basal ganglia. The basal ganglia refer to multiple nuclei in the forebrain that serve a wide number of functions. Some portions support cognitive control and regulation, while others support affective regulation associated with motivation and reward sensitivity (Schultz et al, 2000; Tanaka et al, 2004). Structural alterations in basal ganglia regions are not typically observed in child and adolescent samples. However, two studies involving adolescents who report retrospectively on histories of childhood maltreatment show alterations in the putamen (Liao et al, 2013) and in striatal circuitry more broadly (Edmiston et al, 2011).

Cerebellum. There is growing appreciation for the role of the cerebellum in supporting higher-level learning and cognition; it has extensive connections with the frontal lobe and is part of a critical fronto-cerebellar network that modulates behavior; further, the development of certain cerebellar regions are highly shaped by experience (Leiner et al, 1991; Kim et al, 1994; Giedd et al, 2007).

Structural changes in the cerebellum have consistently emerged in studies involving children exposed to maltreatment. Relative to healthy controls, maltreated children with PTSD showed reductions in total cerebellar volumes; further, cerebellar size was positively associated with the age of onset of the maltreatment, but negatively associated with the duration of the maltreatment experience that led to PTSD (De Bellis and Kuchibhatla, 2006). Relative to controls, decreases in the vermis, a subregion of the cerebellum that is relatively protracted in its development and sensitive to stress (Anderson et al, 2002), has been shown in two studies involving maltreated youth with and without PTSD (Carrion et al, 2009; Hanson et al, 2010). In a study involving adolescents, higher self-reported exposure to physical neglect was associated with reduced cerebellar volumes (Edmiston 
et al, 2011). A study involving maltreated children found increases in cerebellar white matter content with concomitant decreases in the vermis, relative to controls (Hanson et al, 2010).

Structural connectivity. In recent years, there has been growing interest in understanding how maltreatment affects the structural connectivity of the brain, specifically involving neural pathways that support communication between critical brain regions. Studies examining maltreatmentinduced differences in white matter content (myelinated bundles of neurons that connect disparate regions of the brain) have provided some information on this topic.

The corpus callosum is the largest white matter tract in the brain and supports neural transmission across the hemispheres. Reductions in total corpus callosum volumes and its subregions (anterior and posterior mid-body and splenium) have been consistently observed (De Bellis et al, 2002; Teicher et al, 2004; Carrion et al, 2009) among children exposed to childhood maltreatment, relative to controls. Given its role in higher-level cognitive and emotional functioning, alterations in this structure may contribute to risk for a number of difficulties.

Diffusion tensor imaging (DTI) provides quantitative estimates of the microstructural properties of discrete white matter tracts, and has therefore allowed for a more detailed understanding of structural connectivity differences that result from childhood maltreatment. Reductions in fractional anisotropy (FA), an indicator of white matter organization and myelination, have been shown in anterior and posterior mid-body subregions of the corpus callosum in children exposed to childhood maltreatment, relative to controls (Jackowski et al, 2008). Adolescents who retrospectively report exposure to childhood maltreatment were reported to show reduced FA in the splenium of the corpus callosum, relative to controls (Huang et al, 2012). In addition to the corpus callosum, long association fibers (the superior longitudinal fasciculus and the inferior longitudinal fasciculus), and tracts involved in limbic circuitry (the cingulum) were shown as affected by childhood maltreatment exposure. These disruptions may point to alterations in network organization of the brain secondary to maltreatment, which may underlie risk for cognitive and emotional difficulties. It is important to note that majority of studies that link maltreatment-associated white matter alterations with cognitive and/or emotional functioning are cross-sectional. Longitudinal studies will help clarify whether these neural changes preceded cognitive or emotional difficulties.

\section{Consequences of Maltreatment on Brain Function}

A growing body of work has examined functional changes in brain activity among children with and without exposure to childhood maltreatment (Table 1). Functional alterations have typically been examined while youth participate in tasks requiring cognitive regulation, when processing social or emotional stimuli, or during 'resting state' assessments of functional brain activity.

Functional alterations during cognitive tasks. Global deficits in executive functioning (eg, involving inhibitory control, working memory, planning, cognitive flexibility, and sustained attention) are often observed in children exposed to maltreatment (Pechtel and Pizzagalli, 2011). There are growing attempts to identify disruptions in neural circuitry that contribute to these delays (Hart and Rubia, 2012).

Several studies have used fMRI to examine maltreatmentassociated alterations in neural functioning during cognitive tasks that require executive functioning. In one study, individual differences in attention and cognitive control was assessed while youth participated in an "oddball" task involving non-emotional targets and task-irrelevant emotional distractors. Relative to controls, maltreated youth with co-morbid depressive disorders showed decreased neural activation in cognitive control circuits (in the middle frontal gyrus and precentral gyrus) in response to non-emotional attention targets, and increased neural activation in ventral emotional circuits (in the amygdala, subgenual cingulate, inferior frontal gyrus, and middle temporal gyrus) in response to negatively-valenced emotional distractors; (De Bellis and Hooper, 2012). As youth also met criteria for depression, it is unclear whether these alterations are due to current psychiatric status or exposure to prior trauma.

Neural activation differences have also been assessed in tasks involving inhibitory control, the ability to inhibit a prepotent response and ignore distracting and irrelevant information. In one study, youth with PTSD secondary to interpersonal violence exposure (physical, sexual abuse, or family violence) did not significantly differ in their behavioral performance relative to controls. However, they showed relatively decreased activation in middle frontal brain regions, and increased activation in medial frontal regions (medial frontal gyrus and the anterior cingulate cortex) when exerting inhibitory control during the task (Carrion et al, 2008).

A recent study examined inhibitory control and associated neural functioning among maltreated children who were removed from their biological families and placed into foster care. Relative to healthy controls, foster children showed decreased activation in the anterior cingulate cortex and increased activation in the left inferior parietal lobule and right superior occipital cortex, when required to demonstrate inhibitory control (Bruce et al, 2013). These neural activation differences were considered indicative of alterations in neurodevelopmental organization in networks that support higher-level cognition.

In a more recent study, adolescents exposed to severe physical abuse during childhood participated in a "stopsignal" task, which measures the inhibition of a response that has already been initiated, and were compared with children without histories of abuse. No behavioral differences between groups were observed. However, in response to incorrect 
TABLE 1 Summary of Associations Between Childhood Maltreatment and Brain Morphology Revealed by Structural MRI

\begin{tabular}{|c|c|c|c|c|c|c|c|c|c|c|c|}
\hline Authors (year) & $\begin{array}{l}\text { Imaging } \\
\text { method }\end{array}$ & Global Brain Vm & Amygdala & Hippocampus & $\mathrm{PFC}$ & Corpus callosum & Cerebellum & $\begin{array}{l}\text { WB } \\
\text { or } \\
\text { ROI }\end{array}$ & ROI method & Timing effect & Other Sig regions \\
\hline De Bellis et $a$, 1999 & sMRI & $\begin{array}{l}\text { ICV: PTSD CM<HC; CV: } \\
\text { PTSD CM < }<\text { C C cortical } \\
\text { gray NS; } \\
\text { cortical white: NS }\end{array}$ & NS & NS & NS & $\begin{array}{c}\text { PSTD CM }<\text { <ontrol, (CC: A, P, } \\
1, M, S)\end{array}$ & & $\mathrm{ROI}$ & $\begin{array}{l}\text { Global: AS; ROIs: } \\
\text { MT }\end{array}$ & $\mathrm{ICV}$ and $\mathrm{CC}$ & \\
\hline De Bellis et $a, 2001$ & sMRI & NS & NS & NS & & & & ROI & MT & & \\
\hline Carrion et al, 2001 & sMRI & $\begin{array}{l}\text { CV: PTSD CM }<\text { CHC; left FL: } \\
\text { PTSD CM < <C i uncorr. } \\
\text { for GM but > } \mathrm{HC} \text { if } \\
\text { corrected for GM }\end{array}$ & NS & NS & & & NS & ROI & $\begin{array}{l}\text { Global: AS; amyg: } \\
\text { MT; hippo: MT }\end{array}$ & & \\
\hline De Bellis et $a, 2002$ & sMRI & $\begin{array}{l}\text { ICV: PTSD CM<HC; CV: } \\
\text { PTSD CM < }<\text { HC }\end{array}$ & NS & NS & NS & $\begin{array}{c}\text { PTSD CM<HC (CC: A, P, I, } \\
\text { M, S ) }\end{array}$ & & ROI & MT & $\mathrm{ICV}$ and $\mathrm{CV}$ & \\
\hline Teicher et $a l, 2004$ & sMRI & & & & & $\begin{array}{l}\text { CM with Psy Dis< }<\text { sy Dis only } \\
\text { and HC (CC: A, P, M) }\end{array}$ & & $\mathrm{ROI}$ & AS & & \\
\hline Tupler and De Bellis, 2006 & sMRI & & & $\begin{array}{l}\text { Tot Vm: PTSD CM> HC (right); } \\
\text { HWM: PTSD CM > HC (bilat); } \\
\text { HGM: NS }\end{array}$ & & & & ROI & AS & $\begin{array}{l}\text { Tot Vm of hippocampus } \\
\text { (bilat): HWM (bilat); }\end{array}$ & \\
\hline Richert et $a, 2006$ & SMRI & & & & PTSD CM> HC (mid. infer, vmPFC) & & & ROI & AS & & \\
\hline De Bellis and Kuchibhata, 2006 & SMRI & $\begin{array}{l}\text { ICV: PTSD CM<HC } \\
\text { CV: PTSD CM }<H C\end{array}$ & & & & & $\begin{array}{l}\mathrm{PTSD} \mathrm{CM}<\mathrm{HC} \\
\text { (bilat.) }\end{array}$ & ROI & MT & Cerebellum & \\
\hline Carrion et al, 2007 & SMRI & & & $\begin{array}{l}\text { PTSD sympt neg, assoc. hippo. } \\
\text { change over time (right) }\end{array}$ & & & & $\mathrm{ROI}$ & MT & & \\
\hline Carrion et al, 2009 & sMRI & $\begin{array}{l}\text { ICV: PTSD CM<HC } \\
\text { OL GM: PTSD CM>HC }\end{array}$ & & & PTSD CM > HC (inf, sup., vPFC) & NS & $\begin{array}{l}\text { Posterior vemis: } \\
\text { PTSD CM<HC } \\
\text { (posterior) }\end{array}$ & $\begin{array}{c}\text { ROI } \\
\& \\
\text { WB }\end{array}$ & $\begin{array}{l}\text { PFC ROIs: AS } \\
\text { CC, vemis, } \\
\text { brainstem ROls: } \\
\text { MT }\end{array}$ & & Pons: PTSD CM<HC \\
\hline U. Rao et $a, 2010 \mathrm{~b}$ & SMRI & & & CM neg. assoc. hippo. vm (bilat) & & & & $\mathrm{ROI}$ & MT & & \\
\hline Rao et $a, 2010 a$ & sMRI & & & $\begin{array}{l}\text { Par. nurt. at age } 4 \text { neg. assoc. hippo. } \\
\qquad m \text { (bilat.) }\end{array}$ & & & & $\begin{array}{l}\text { ROI } \\
\text { and } \\
\text { WB }\end{array}$ & MT: hippo. & & $\begin{array}{l}\text { Par. nurt at age } 4 \text { negg. assoc. } \\
\text { middle cingulate, thalamus }\end{array}$ \\
\hline Hanson et al, 2010 & $\begin{array}{l}\text { sMR// } \\
\text { TBM }\end{array}$ & & & & $\begin{array}{l}P A<H C \text { (right, OFC, dIPFC, vmPFC, frontal } \\
\text { cortex; lefts superior frontal lobe, dPPC) }\end{array}$ & & $\begin{array}{l}\text { PA> HC (left } \\
\text { WM, lateral, right: } \\
\text { WMM) } \\
\text { PA }<H C \text { (vermis) }\end{array}$ & WB & & & 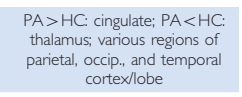 \\
\hline Lupien et al, 2011 & sMRI & & NS & MDE $>$ no HC (bilat) & & & & ROI & MT & & \\
\hline Edmiston et $a, 2011$ & sMRI & & $\begin{array}{l}\text { CM neg, assoc. with amygdala } \\
\text { (nght) }\end{array}$ & & $\begin{array}{l}\text { CM neg. assoc. with bilat. Il, billat, rostral, left } \\
\text { subgeneal PFC }\end{array}$ & & $\begin{array}{l}\text { CM neg. assoc. } \\
\text { with cerbellum } \\
\text { (bilat) }\end{array}$ & WB & & & $\begin{array}{l}\text { CM neg. assoc. with striatum, } \\
\text { bilat, hypothal, midbrain, various } \\
\text { regions of parietal, occip., and } \\
\text { temporal cortexllobe }\end{array}$ \\
\hline Luby et $a, 2012$ & sMRI & & NS & $\begin{array}{l}\text { Mat. sup. pos. assoc. } \\
\text { hippo. vm (bilat). }\end{array}$ & & & & ROI & AS & & \\
\hline De Brito et al, 2013 & sMRI & $\begin{array}{l}\text { ICV: NS: GM: CM<HC; } \\
\text { WM: NS }\end{array}$ & NS & NS & $\begin{array}{l}\text { OFC: } \\
\mathrm{CM}<\mathrm{HC}\end{array}$ & & NS & $\begin{array}{l}\mathrm{ROI} \\
\& \\
\mathrm{WB}\end{array}$ & $\begin{array}{l}\text { AS: amyg., hippo., } \\
\text { PFC, temporal } \\
\text { lobe, cerebellum }\end{array}$ & & $\mathrm{CM}<\mathrm{HC}$ mid temporal gyrus \\
\hline Whittle et $a 1,2013$ & SMRI & & $\begin{array}{l}\text { CM neg. assoc. change in amygdala } \\
\text { mm over time (not assoc. with } \\
\text { baseline) (tight) }\end{array}$ & $\begin{array}{l}\text { CM pos. assoc. hippo. } \\
\text { vm at baseline (not assoc. } \\
\text { with change over time) (left) }\end{array}$ & 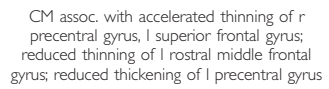 & & & $\begin{array}{l}\text { ROI } \\
\text { and } \\
\text { WB }\end{array}$ & $\begin{array}{l}\text { AS (hippo. and } \\
\text { amyg.) }\end{array}$ & & \\
\hline Kelly et $a l(2013)$ & SMRI & & & & $\begin{array}{l}\mathrm{CM}<\mathrm{HC} \text { t thickness right ventral } A C C / \text { sup } \\
\text { frontal gyrus } 1 \mathrm{OFC}\end{array}$ & & & $\begin{array}{l}\mathrm{WB} / \\
\mathrm{ROI}\end{array}$ & $\begin{array}{l}\text { ROI: AS (for } \\
\text { surface area on } \\
\text { gyrus level) }\end{array}$ & & $\begin{array}{l}C M<H C \text { surface area and LGI: } \\
\text { left lingual gyrus; SA: mid temp } \\
\text { grvus; LG: lett insula/pars } \\
\text { opercularis }\end{array}$ \\
\hline Liao et $a l, 2013$ & sMRI & & NS & NS & NS & & & $\begin{array}{l}\text { WB } \\
\text { and } \\
\text { ROI }\end{array}$ & $\begin{array}{l}\text { AS (amyg., } \\
\text { thalamus, hippo., } \\
\text { insula, PFC) }\end{array}$ & & $\begin{array}{l}\text { Thalamus GAD and } C M>C M \\
\text { only, GAD with no } C M \text {, and HC } \\
\text { (left) }\end{array}$ \\
\hline Hanson et al, 2014 & sMRI & & $\mathrm{PA}<\mathrm{HC}$ (left) & $\mathrm{PA}<\mathrm{HC}$ (night) & & & & $\mathrm{ROI}$ & MT & & \\
\hline
\end{tabular}


trials, abused youth showed relatively increased activation in the anterior cingulate cortex and supplementary motor regions, which are two regions known to support error processing (Lim et al, 2015).

A number of studies have used electrophysiological approaches to assess how maltreatment may alter neural functioning during cognitive tasks. The error-related negativity (ERN) is an electrophysiological component (referred to as an event-related potential; ERP) that arises in response to incorrect responses during tasks that tap inhibitory control. Variability in the magnitude of this response is considered reflective of differences in error monitoring or conflict detection (Coles et al, 2001; Van Veen and Carter, 2002; Herrmann et al, 2004; Arbel and Donchin, 2009; Roger et al, 2010; Hughes and Yeung, 2011) and has been localized to the anterior cingulate cortex, a key neural region also associated with conflict detection and error monitoring (Bush et al, 2000). In a recent study, ERNs were recorded while 6-year-old children completed a go/no-go task requiring inhibitory control. Relative to children reared in responsive families, children exposed to harsh parenting during infancy showed greater magnitudes of their ERNs in response to errors of failed inhibition. The magnitude of the ERN response mediated risk for anxiety (Meyer et al, 2014), suggesting a potential neurodevelopmental pathway linking childhood maltreatment with regulatory difficulties.

Childhood maltreatment is long known to confer risk for academic difficulties and learning problems (Pechtel and Pizzagalli, 2011). This has prompted interest in understanding how maltreatment may lead to functional alterations in subcortical structures that support learning and memory. Given its well-known role in memory development, the hippocampus is one region of interest (Jabes and Nelson, 2015, ahead of print). In one study, children and adolescents with histories of violence exposure and PTSD showed reduced hippocampal activation when retrieving information during a declarative memory task, relative to healthy controls (Carrion et al, 2010).

Functional alterations to social and emotional input. Several studies have investigated whether childhood maltreatment exposure leads to altered neural responses to emotional stimuli, as a potential mechanism explaining increased psychosocial risk. On a behavioral level, children exposed to maltreatment show alterations in processing of social and emotional stimuli. Patterns suggest attentional biases toward threatening emotional cues (da Silva Ferreira et al, 2014), which may reflect maladaptive patterns of social information processing, and/or signal difficulties with emotional or stress regulation. A growing body of work has examined the extent to which these behavioral differences can be observed at the level of the brain, which may provide insight into mechanisms subserving risk.

One line of work has utilized fMRI to examine variation in neural responses to emotional and social stimuli. Infants exposed to higher levels of inter-parental conflict have shown relatively greater activation in brain regions critical for emotion processing and stress regulation (including the anterior cingulate cortex, the caudate, the hypothalamus, and thalamus) in response to the sound of their mothers' angry voice (Graham et al, 2013). School-age children reared in contexts of high family violence have also shown relatively increased insula and amygdala responses to threatening emotional faces (McCrory et al, 2011b). Maltreated youth have also shown relatively increased amygdala activation in response to preattentively presented angry and happy faces, with age of onset predictive of the degree of activation (De Brito et al, 2013). Two studies have shown associations between emotional neglect in family settings and increased levels of amygdala activation to angry and fearful faces (Bogdan et al, 2012; White et al, 2012). Similar findings have been observed in a mixed sample of youth exposed to neglect in family settings and in institutional rearing (Maheu et al, 2010).

ERPs to emotional stimuli have also been examined in a number of studies involving maltreated infants, toddlers, and school-age children. Across several studies, findings suggest that children reared in physically abusive families exhibit relatively increased ERP amplitudes to angry emotional cues from unfamiliar faces. This has been observed in occipital (P1, P4), fronto-central (P260; Nc) and parietally (P3) assessed components (Cicchetti and Curtis, 2005; Curtis and Cicchetti, 2011; 2013; Pollak et al, 1997; Pollak et al, 2001; Shackman and Pollak, 2014). In another study, maltreated children showed relatively greater P3 responses to their mothers' angry face $v s$ an unfamiliar face, and greater P3 responses to angry voices, regardless of familiarity (Shackman et al, 2007). These neural response biases were considered reflective of hyper-responsiveness or vigilance to threatening emotional cues. There is some evidence that these biases increase risk for anxiety (Shackman et al, 2007) and propensity for negative affect during adverse peerinteractions (Shackman and Pollak, 2014). Therefore, these neural differences may underpin risk for emotional difficulties.

Functional alterations during 'resting states'. Although less common, baseline or 'resting state' neural activation patterns (ie, neural activity that arises when a person is not explicitly engaged in task) have been investigated in association with childhood maltreatment.

The majority of work involving maltreated children has relied on electroencephalography (EEG) to address this question. Frontal EEG asymmetry, or the relative difference in resting frontal EEG across hemispheres, is widely used as a marker of frontal cortex activation. The left frontal cortex is activated by positive emotional stimuli and is associated with approach behavior. In contrast, the right frontal cortex is activated by negative emotional stimuli and has been associated with avoidance or withdrawal (Davidson and Fox, 1982; Davidson et al, 1990; Fox, 1991; Davidson, 1992). Consistent with these patterns, EEG asymmetry profiles indicative of relatively greater right frontal cortex activation 
have been correlated with increased emotional reactivity, behavioral inhibition, and psychopathology (Davidson, 1993). Given clinical implications, there has been some effort to examine EEG asymmetry profiles in maltreated children. In one study, children exposed to maltreatment showed EEG asymmetry reflective of greater right frontal cortex activation, which may signal biases toward negative emotional information, and indicate risk for emotional maladjustment (Miskovic et al, 2009).

EEG coherence, or phase synchrony in oscillatory brain activity, is another indicator of brain function that has been applied to samples involving maltreated youth. Thatcher et al (1986) have reported lower EEG coherence among electrodes in close proximity to one another, which can indicate greater local network complexity and increased cortical differentiation or maturity. In two studies, maltreated youth have shown higher shortdistance coherence in the left hemisphere relative to nonmaltreated youth (Ito et al, 1998; Miskovic et al, 2010). This suggests that maltreatment exposure may lead to delays in cortical differentiation or maturation, which may underpin risk for a broad range of emotional and cognitive difficulties.

Functional connectivity. Higher-level emotional and cognitive functions arise from complex activity between neural network pathways. Therefore, there is growing interest in understanding potential perturbations in activation of critical neural pathways that support higher-level functioning. However, relative to other areas of neural functioning, the extent to which maltreatment may interfere with functional connectivity between critical brain regions is much less researched. A recent study examined alterations in resting state functional connectivity between frontal and limbic regions in adolescents who self-reported maltreatment. Results indicated that retrospectively reported maltreatment histories were inversely associated with hippocampussubgenual cingulate activity for males and females; further, lower amygdala-subgenual cingulate activity was observed for females, which also significantly mediated risk for internalizing symptoms (Herringa et al, 2013).

\section{Early Intervention and Childhood Maltreatment}

To our knowledge, only one study has examined the extent to which early intervention can support normalization in brain development in children exposed to childhood maltreatment. In this study, children with histories of maltreatment were randomly assigned to a preventive intervention, the Multidimensional Treatment for Foster Care-Preschoolers program (Fisher et al, 1999). This intervention was designed to decrease behavioral difficulties for preschool age children placed into foster care. As part of this treatment, foster parents were trained to provide responsive care to foster children in their care. Foster parents were also trained to support the child's transition if moved to another placement (such as to adoptive family, other long-term placement, or reunification with biological family).

Following treatment, ERPs were recorded during tasks requiring sustained attention and inhibitory control in three groups of children: foster children who received the intervention, foster children who received care as usual, and non-maltreated children from the community. As part of this task, children received positive feedback to correct responses and negative feedback to incorrect responses. There were no significant differences in behavioral performance across groups. However, children who received early intervention showed improvements in their feedback-related negativity (the FRN), a negative-deflecting ERP component that arises in response to feedback. Specifically, non maltreated children and foster children who received the intervention and children showed relatively greater magnitudes of the FRN to negative $v s$ positive feedback. However, foster children who received treatment as usual did not show differences in their responses to negative $v s$ positive feedback conditions (Bruce et al, 2009). These findings suggest that early intervention can support normalization in performance monitoring during attention tasks, which may reflect more optimal levels of vigilance and attention to errors, a process that may be necessary for learning and academic success.

\section{INTERIM SUMMARY: CHILDHOOD MALTREATMENT}

In summary, there is growing evidence that children exposed to early adverse rearing in maltreating family contexts show neurodevelopmental alterations that increase risk for cognitive and emotional maladjustment. Maltreatmentassociated changes have been observed in key limbic structures, particularly the hippocampus and amygdala, both functionally and structurally, yet there is notable variability in findings across studies. Growing evidence also supports structural variations in areas of the prefrontal cortex that are known to support attention and emotional control; yet, patterns of results are also variable. Functional alterations in activation of the anterior cingulate cortex during tasks requiring cognitive control have been observed in several studies; these findings converge with neural activation patterns identified in electrophysiological studies using similar cognitive tasks. Although less studied, a growing body of work supports changes in additional subcortical structures that subserve cognitive and emotional functioning (ie, the basal ganglia and cerebellum). Finally, there is converging evidence that exposure to maltreatment may not only affect discrete regions of the brain, but may also interfere with the formation of critical network pathways. There is promising evidence that early intervention can support normalization in activation of key circuitry related to cognitive control; the extent to which this reduces the risk for attentional or cognitive-related difficulties should be examined in future work. 


\section{INSTITUTIONAL REARING}

According to recent estimates, approximately eight million children currently reside in institutional settings (Committee on the Rights of the Child, United Nation's Children's Fund, 2004; UNICEF, 2007). In institutions, children typically encounter a 'species-atypical' rearing experience, in that they are deprived from the opportunity to develop attachment relationships with stable, primary caregivers. As part of institutional rearing, children also miss out on critical sensory, cognitive, linguistic, and emotional input that supports typical brain development. This severe psychosocial deprivation leads to compromises in a number of developmental domains, ranging from poor physical growth, cognitive delays, and increased risk for psychiatric disorders (Kreppner et al, 2001; Rutter et al, 2001; Stevens et al, 2008; Zeanah et al, 2009; van et al, 2011; Spratt et al, 2012; MacKenzie et al, 2014). Although adverse consequences of extreme childhood neglect have been known for decades (Spitz, 1945; Kreppner et al, 2001; MacLean, 2003; Rutter and O'Connor, 2004), only recently have the neurobiological changes underlying these effects been elucidated.

In the sections that follow, we first review evidence from studies examining brain development in postinstitutionalized internationally adopted children. Next, we review evidence from the Bucharest Early Intervention Project (BEIP), a randomized clinical trial of foster care in Bucharest Romania for institutionally reared children.

\section{Consequences of Institutional Rearing on Brain Structure}

Global volumetric changes. In a number of studies, neurodevelopment of children adopted out of institutional rearing facilities has been compared with that of typically developing children (Table 2). Studies involving MRI have provided converging evidence for smaller head sizes and associated reductions in brain volumes, as well as decreases in the total gray matter and white matter content in previously institutionally reared children, relative to controls (Eluvathingal et al, 2006; Mehta et al, 2009b; Sheridan et al, 2012; Hanson et al, 2014). Institutionally reared children have also shown widespread alterations in cortical gray matter thickness, which further predicted risk for inattention and ADHD (McLaughlin et al, 2013).

Limbic circuitry. There is mixed evidence on the degree to which institutional rearing affects the development of subcortical brain structures. Both smaller (Hanson et al, 2014) and larger (Mehta et al, 2009b; Tottenham et al, 2010) amygdala volumes have been observed in institutionally reared children relative to healthy controls. These opposing findings have been discussed as potentially related to a number of factors. First, there may be non-linear patterns of amygdala growth following adversity, with increases ocurring early on, which are followed by long term volumetric decreases. Second, findings may vary as a result of the methods used to provide volumetric estimates of these subcortical regions (ie, the use of hand tracing $v$ s automated segmentation; Hanson et al, 2014). There is some evidence that the magnitude of the volumetric change co-varies as a function of the length of time in the institutional environment (Mehta et al, 2009b; Tottenham et al, 2010). Cumulative life stressors, including those experienced after removal from institutional rearing, have also been associated with the magnitude of the decrease (Hanson et al, 2014). Amygdala alterations have been associated with increased risk for behavioral problems (Hanson et al, 2014) and internalizing symptoms (Tottenham et al, 2010).

Alterations in the hippocampus are typically not observed in children exposed to institutional rearing. However, smaller hippocampal volumes have been observed in one study, which compared institutionally reared children adopted into family environments with healthy controls (Hodel et al, 2015). Importantly, reductions were only significant for children adopted at older ages, suggesting that the timing or duration of the neglect may affect the degree to which the hippocampus is affected. Other studies have not shown hippocampal volume changes in institutionally reared children relative to controls (Tottenham et al, 2010; Sheridan et al, 2012; Hanson et al, 2014).

Frontal regions. Morphological changes in the prefrontal cortex have been observed in two studies involving institutionally reared children. Both of these studies investigated whole-brain changes in cortical thickness and surface area in institutionally reared children relative to controls. In one study, for the institutionally reared children, relatively reduced surface area was observed in number of PFC regions (middle frontal gyrus, orbital frontal cortex, and anterior cingulate cortex), but most strongly in the superior frontal gyrus and pars orbitalis; Reduced thickness was also observed in the pars orbitalis, but only for late adopted institutionally reared children relative to controls (Hodel et al, 2015). Reduced cortical thickness of the orbital frontal cortex has also been observed in institutionally reared children, relative to controls (McLaughlin et al, 2013).

Cerebellum. Reductions in cerebellar volumes in institutionally reared children have also been documented relative to controls (Bauer et al, 2009), and have been connected with difficulties involving cognitive control and memory.

Structural connectivity. Alterations in white matter organization using DTI has been shown in previously institutionally reared children relative to controls. Affected fiber tracts were located in fronto-limbic circuitry (the uncinate fasciculus, cingulum and fornix; Eluvathingal et al, 2006; Govindan et al, 2010; Hanson et al, 2013; Kumar et al, 2013; Kumar et al, 2014), frontal striatal pathways (corona radiata, anterior thalamic radiation; Behen et al, 2009; Kumar et al, 2013), language pathways (the arcuate facisculus; Kumar et al, 2014), sensory pathways (forceps, and corticospinal tract; Hanson et al, 2013), and long associations fibers throughout the brain (ie, the interior longitudinal fasciculus, 
inferior frontal occipital fasciculus; Hanson et al, 2013). These white matter alterations have been associated with increased risk for externalizing symptoms (Kumar et al, 2013), poor executive functioning (Hanson et al, 2013), and delays in language development (Kumar et al, 2013).

\section{Consequences of Institutional Rearing on Brain Function}

Relative to documented changes in brain morphology there are fewer investigations on the impact of severe early life neglect on brain function. However, evidence from a handful of studies involving postinstitutionalized adopted children point to alterations in functional activity of the developing brain.

Functional alterations during cognitive tasks. fMRI has been used to examine alterations in neural activity during inhibitory control tasks in children with and without exposure to institutional rearing. In one study, youth participated in a go/no-go task that occasionally required children to shift attention to new target information, thus assessing abilities to exert inhibitory control and demonstrate cognitive flexibility. Institutionally reared children did not significantly differ in their overall accuracy relative to non-institutionalized youth. However, relative to controls, they took longer to switch from a prepotent 'go' response to the alternative, non-prepotent response. Further, they showed relatively increased activation in brain regions associated with conflict monitoring (ie, dorsal anterior cingulate cortex) and inhibitory and response control (ie, inferior prefrontal cortex and striatum), as well as in the insula, and sensorimotor regions (Mueller et al, 2010). These activation differences suggest potential developmental alterations in circuitry that supports cognitive control.

Functional alterations to social or emotional input. Using fMRI, increased amygdala activation to negative emotional expression levels have been observed in two studies involving institutionally reared children relative to controls (Tottenham et al, 2011; Maheu et al, 2010). Children who spent more time in institutional care and/or less time in adoptive homes showed higher levels of amygdala activation, suggesting that effects may depend on the duration of the neglect (Tottenham et al, 2011; Maheu et al, 2010). In another study, amygdala responses were examined while children viewed images of their caregiver's face versus that of a stranger. Family reared children showed significantly greater relative amygdala activation to their caregiver's face vs the stranger's face. However, institutionally reared children showed no significant differences in their amygdala response to caregiver and stranger faces (Olsavsky et al, 2013). There is evidence that these functional alterations have specific relevance for emotional adjustment, as they have been associated with increased risk for disinhibited social behavior (Tottenham et al, 2011; Olsavsky et al, 2013) 
and reduced eye contact in social interactions (Tottenham et al, 2011).

Functional alterations to reward. Functional alterations in the basal ganglia have been observed when institutionally reared and family reared youth completed tasks involving monetary reward anticipation. There were no significant differences in the behavioral performance on this task across groups. Yet, group differences were observed on a neural level. While children reared in family settings showed increased ventral striatum and caudate response to reward, these activation patterns were not observed in institutionally reared children (Mehta et al, 2009a). This suggests that institutionally reared children may show alterations in their sensitivity to rewarding stimuli, which may place them at risk for a number of affective difficulties.

Functional alterations during 'resting states'. Resting brain activity has been examined using positron emission tomography in institutionally reared children relative to controls. In this seminal study, institutionally reared children exhibited reductions in levels of glucose metabolism, specifically in prefrontal regions (the orbital frontal gyrus and infralimbic prefrontal cortex), in the medial temporal lobe (amygdala and hippocampus), in the lateral temporal cortex, and the brainstem (Chugani et al, 2001).

Functional connectivity. To date, only one study has examined how exposure to institutional rearing may interfere with functional connectivity in the brain. In this study, institutionally reared children showed atypical patterns of connectivity between the ventromedial prefrontal cortex and the amygdala. These neural connectivity differences were also associated with increased anxiety symptoms (Gee et al, 2013). This suggests that early life neglect may interfere with fronto-limbic connectivity known to support emotion processing and stress regulation.

\section{EARLY INTERVENTION AND INSTITUTIONAL REARING}

The BEIP is the first randomized clinical trial of foster care as an intervention for institutionally reared children (Zeanah et al, 2003). As part of this investigation, children reared in an institution in Bucharest, Romania were randomly selected to be removed from the center and were placed into high-quality foster care during early childhood. The development of these children has been compared with that of children who remained in the institution, and also to a comparison group of non-neglected children.

\section{Global Volumetric Changes}

Between 8 and 10 years of age, children in the BEIP participated in structural MRI scanning, allowing for an examination of potential long-term consequences of early life neglect on cortical and subcortical brain development
(Figure 1). Results indicated that, relative to controls, children exposed to institutional rearing showed decreased cortical gray matter volumes, and reduced thickness throughout the cortex. Children placed in foster care did not significantly differ from children who remained in the institution, suggesting limited effects of the intervention in supporting long term remediation in cortical or subcortical gray matter development (Sheridan et al, 2012; McLaughlin et al, 2013). However, total white matter volumes varied as a function of early intervention status; children who were placed into foster care did not significantly differ in their total white matter volumes from children reared in biological families; yet, children who remained in the institution showed significantly decreased white matter volumes when compared with the never institutionally reared children (Sheridan et al, 2012). There is some evidence that alterations in cortical thickness, secondary to neglect, predict risk for inattention and hyperactivity (McLaughlin et al, 2013).

\section{Structural Connectivity}

Estimates of white matter microstructure were quantified from the MRI scans collected when children were between 8 and 10 years of age (Figure 2). Findings revealed that institutional rearing was associated with reduced integrity of the body of the corpus callosum No significant intervention effect was observed in this region. However, there was evidence for intervention-based remediation in select fiber tracts in fronto-limbic circuitry (fornix, cingulum), frontostriatal circuitry (external capsule, coronal radiata), and in white matter tracts involved in more basic sensory processes (medial lemniscus, retrolenticular limb of the internal capsule; Bick et al, 2015). These findings point to the potential for early intervention to normalize certain aspects of brain development, which may mitigate risk for problematic outcomes.

\section{Functional Changes in the Brain}

EEG collected as part of the BEIP has provided insight into the extent to which removal from institutional rearing and placement into foster care may support improved brain function. Neural functioning has been examined during tasks requiring cognitive control, during processing of social and emotional information, and at resting states.

Functional alterations during cognitive tasks. When children reached 8-10 years of age, electrophysiological brain responses were recorded during two tasks that required inhibitory control, a go/no-go task and a flanker task. Variability in two neural indicators of response monitoring, the ERN and the error-related positivity $(\mathrm{Pe})$ were examined during both of these tasks. The ERN (described in the previous section on maltreatment) is a negative deflecting component that is elicited in response to errors. The Pe is a positive deflecting component that follows the ERN, and is also elicited in response to errors. The Pe is considered 

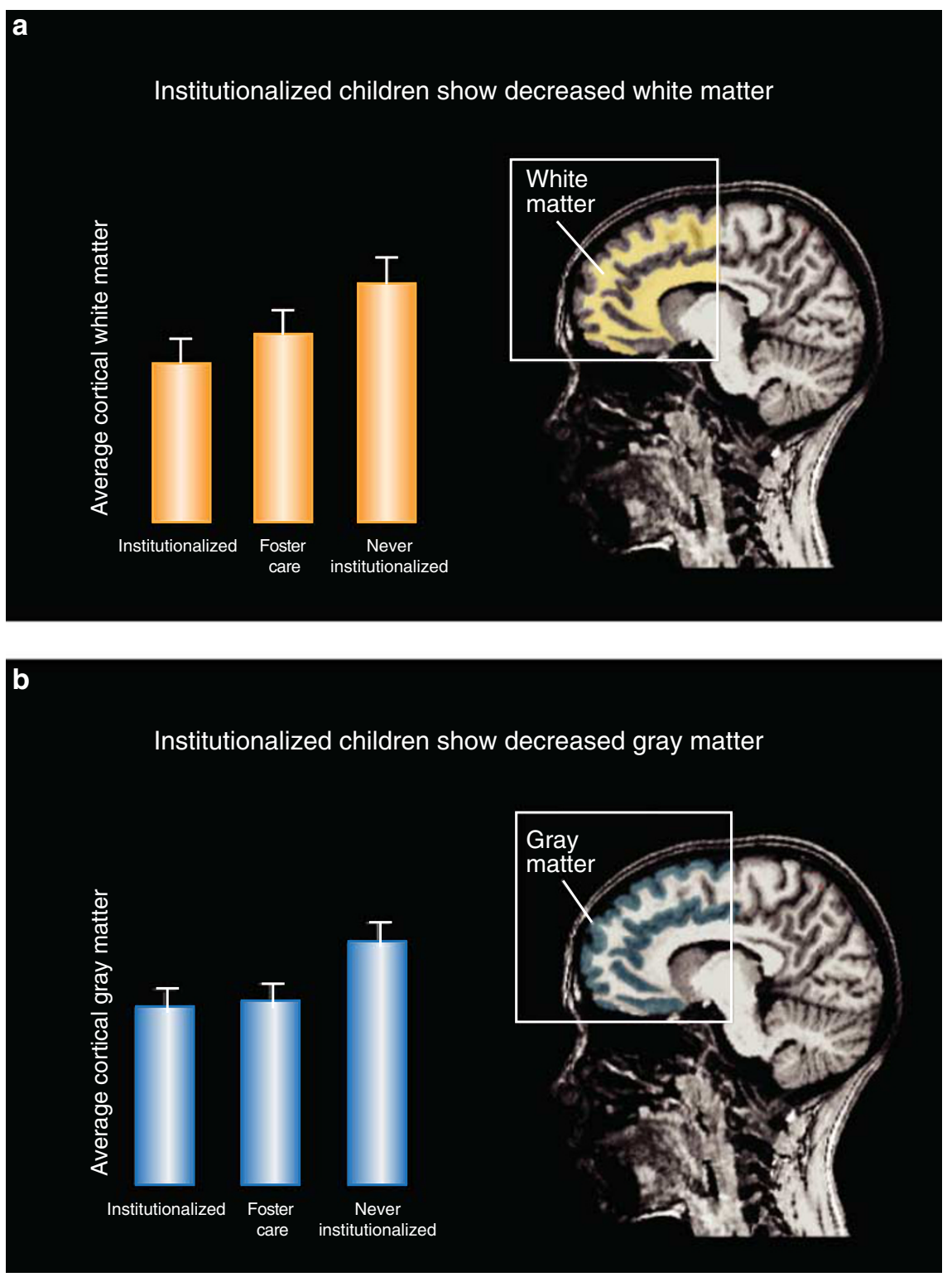

Figure 1. (a) Average total cortical gray matter volume in cubic centimeters $\left(\mathrm{cm}^{3}\right)$ for the CAUG, FCG, and NIG. (b) Average total white matter volume in cubic centimeters $\left(\mathrm{cm}^{3}\right)$ for the CAUG, FCG, and NIG.

reflective of increased conscious evaluation of one's performance (Nieuwenhuis et al, 2001).

Intervention effects were observed for ERPs assessed during both the go/no-go and flanker tasks. In the go/ no-go task, children placed into foster care showed greater accuracy and faster response times than children who remained in the institution. In terms of neural response patterns, children placed into foster care showed greater Pe responses to incorrect trials, than children who remained in the institution. Further, for foster children, greater ERNs were associated with lower reported behavioral problems (McDermott et al, 2013). This suggested that removal from neglect and entry into foster care may support increased error monitoring, which may be adaptive in that it promotes improved self-regulation. Group differences in performance on the flanker task was consistent with these patterns observed during the go/no-go task. Specifically, children placed in foster care showed increased ERNs to incorrect trials, relative to children who remained in the institution (McDermott et al, 2012). Across both tasks, the magnitude of error-related ERPs of children placed into foster care did not significantly differ from that of the non-institutionalized children, suggesting a normalization of neural responses during error processing which may promote adaptive functioning in social emotional or cognitive domains.

Functional alterations to social and emotional input. In the BEIP, ERPs have been examined in response to familiar and unfamiliar faces and also to facial expressions of positive and negative emotions. At the baseline assessment (prior to randomization), institutionally reared children showed significant reductions in the magnitude and/or latency of face- 
a
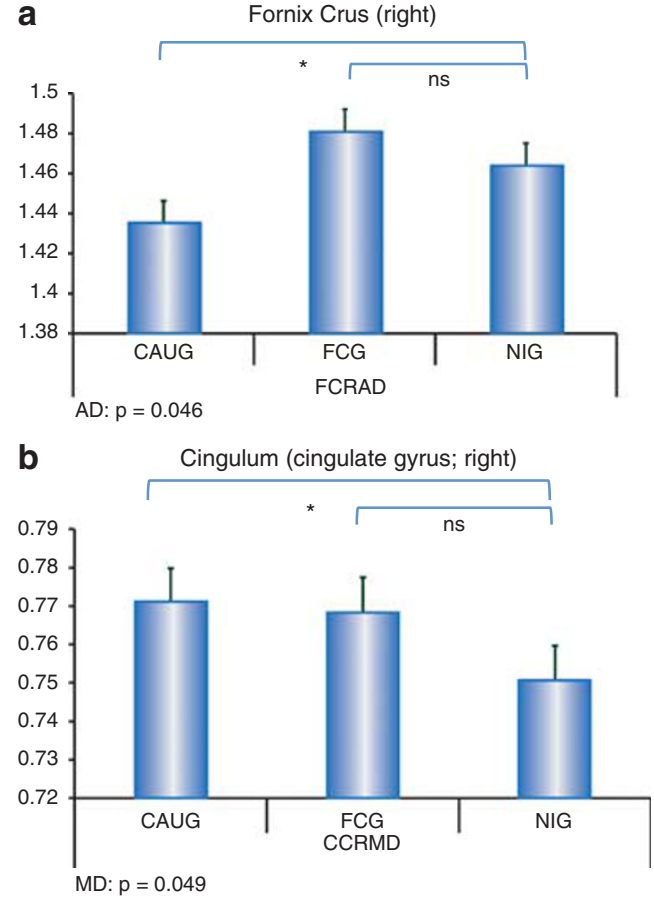

Figure 2. (a) Axial diffusivity of the fornix crus in the CAUG, FCG, and NIG. (b) Mean diffusivity of the cingulum of the cingulate gyrus in the CAUG, FCG, and NIG (note: lower mean diffusivity is indicative of higher integrity).

sensitive ERPs to all face stimuli, relative to never institutionally reared children (Moulson et al, 2009a, b). Further, these altered neural responses predicted risk for inattention and anxiety during the preschool years (Slopen et al, 2012).

By 30 months of age, children in foster care were starting to show differences in ERP responses to faces. However these differences did not reach a statistically significant level until children reached 42 months. At the 42-month assessment, children placed into foster care showed magnitudes of the P1 and N170 (two early occurring ERPs) that fell in between those of children who remained in the institution and children who were reared in family settings (Moulson et al, 2009a,b). Similar patterns were observed in ERPs in response to emotional facial expression levels measured at 8 years of age (Nelson et al, 2013). For both of these studies, children who remained in the institution showed significantly smaller ERPs to faces when compared with noninstitutionally reared children; however, the ERPs of foster children did not significantly differ from either group. This suggests a partial remediation in early face-sensitive neural responses in children placed into foster care. Importantly, remediation in these ERP responses was not observed until children reached 42 months of age. Therefore, these changes may only emerge after prolonged time in a supportive family environment, or alternatively, may not appear until children reach a certain stage of development.
Functional alterations during 'resting states'. There is also evidence that early intervention can support remediation in the functional activity of the brain. Electrophysiological assessments were conducted at a baseline assessment occurring before randomization, and when children reached 30 months, 42 months, and 8 years of age. At baseline, institutional neglect was associated with relatively higher levels of low-frequency neural activity (in the theta band) and lower levels of higher-frequency neural activity (in the alpha and beta range), relative to never institutionally reared children (Marshall and Fox, 2004). This pattern reflects a departure from typical neurodevelopment, in which the amount of high-frequency activity increases, whereas the amount of low-frequency activity becomes less pronounced across development. Further, this atypical neurodevelopmental profile has been observed in children at risk for learning and attention difficulties (Barry et al, 2003; Chabot et al, 2005). In the BEIP, these neural alterations predicted specific risk for ADHD symptoms (McLaughlin et al, 2011). This suggests that changes in cortical functioning that arise from institutional rearing may explain risk for inattention and hyperactivity.

Examinations of brain functioning at follow-up assessments showed that entry into a responsive family setting supported normalization in electrophysiological brain functioning. Although not apparent during early childhood (Marshall et al, 2008), improvements became evident once children reached 8 years of age. Further, only children placed into foster care before age 2 showed evidence for improvement; those that were placed in foster care after 2 years of age were indistinguishable from children who remained in the institution (Vanderwert et al, 2010). These data suggest, first, that improvements in brain functioning may occur through prolonged exposure to responsive and enriching environments (as they were observed once children reached 8 years of age, but not at earlier assessments), and second, that the degree to which children show improvements depends on the developmental timing of the intervention (Figure 3). Collectively, this indicates that there may be sensitive points in development where the brain can benefit from corrective information to facilitate recovery, and also that this recovery may not be observed until significantly later in development.

\section{INTERIM SUMMARY: INSTITUTIONAL REARING}

Children exposed to psychosocially depriving circumstances during institutional rearing show alterations in neurodevelopment, which may explain risk for ongoing delays; many of the alterations observed in institutionally reared children parallel those observed in children exposed to maltreatment in family settings. In terms of limbic system alterations, structural changes have been observed in the amygdala, with the duration of the neglect often predicting greater alterations; however, similar to work involving maltreated youth, the direction of findings varies across studies, with 

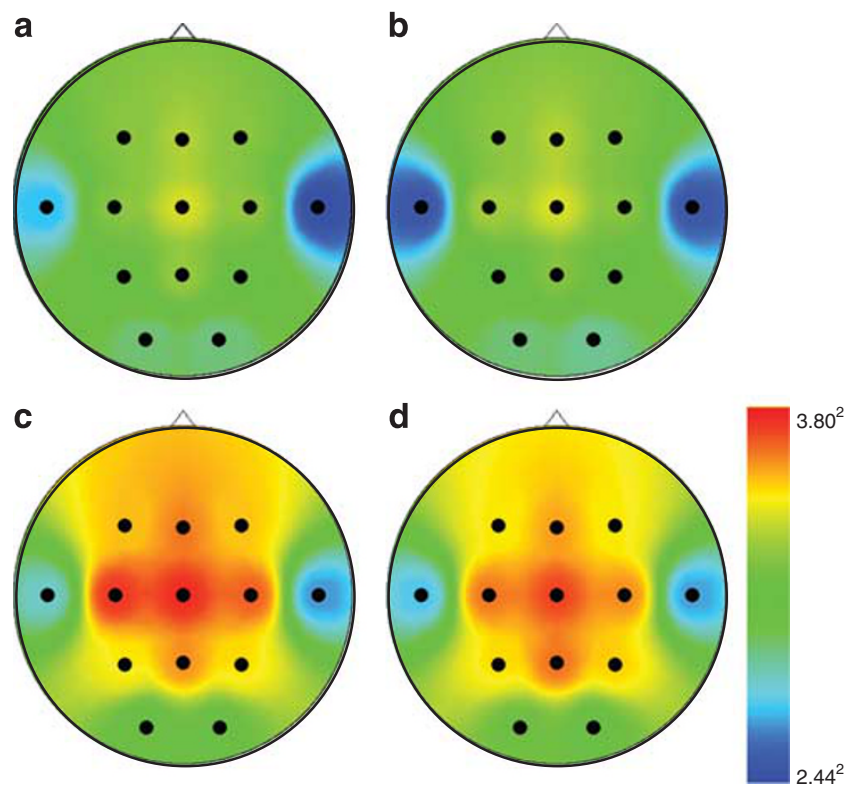

Figure 3. Distribution of alpha power across the scalp for (a) care-as-usual group, (b) foster care group placed after 24 months, (c) foster care group placed before 24 months, and (d) never institutionalized group. This illustrates the timing effects of placement into a family following early institutionalization as reflected in alpha activity. Specifically, in the top left of the figure can be seen the brain activity of the care as usual group (CAUG; ie, institutionalized group). Note that this figure is identical to the figure to the right, which depicts the brain activity of children removed from institutional care and placed in family (foster) care after the age of 24 months. In contrast, the lower left figure reveals the brain activity of children removed from institutional care before 24 months, whereas the figure in the lower right represents the brain activity of the never institutionalized children.

both increases and decreases reported. Increased limbic activity during resting states and heightened amygdala activation to negative emotional cues has also been reported. Hippocampal reductions are not typically reported in institutionally reared children; however, reductions have been observed in institutionally reared children who have more prolonged histories of institutional rearing. Increased activation of frontal regions associated with emotion regulation, and in middle frontal regions associated with error monitoring and conflict detection, have also been observed. These findings point to potential pathways to emotional dysregulation and inattention. Increased activation in striatal regions to rewarding input have also been observed, potentially underlying risk for a range of affective disorders. Connectivity differences have been observed on structural levels in white matter tracts that support higherlevel functioning. Differences have also been observed functionally, as shown by atypical fronto-limbic connections that support emotional control. There is growing evidence that these alterations increase risk for internalizing, externalizing, and social difficulties during later childhood.

Findings from the BEIP, the first longitudinal, prospective, randomized clinical trial of foster care, show evidence for neural remediation on multiple levels of brain development. However, patterns of recovery are complex. Some aspects of neurodevelopment (ie, white matter development) may be more responsive to environmental enrichment than others (ie, cortical gray matter development). Similarly, some remediation in neural responses (ie, cortical arousal measured with EEG) may depend on the timing of the intervention (which, of note, is often conflated with the duration of neglect). Although improvements in EEG activity are observed for children who receive intervention at earliest ages, other aspects of neural improvement (ie, neural responses associated with error monitoring or processing social information with ERP) do not appear to be associated with intervention timing. Finally, some aspects of neural recovery may emerge more immediately (ie, neural responses to social information measured), whereas other aspects may take time to emerge (ie, improvements in cortical activation at rest).

\section{GENERAL CONCLUSIONS}

The accumulating body of evidence provides substantial insight into how childhood maltreatment and psychosocial deprivation experienced via institutional rearing shape the developing brain. Considering findings across studies, data point to functional and structural changes in multiple systems throughout the brain. Evidence is beginning to provide a picture for how changes in brain development may give rise to emotional and cognitive difficulties. Despite significant progress, there are currently more questions than answers. As shown in this review, there is significant heterogeneity in findings across studies. A large number of factors likely contribute to this variability. For example, age of onset, severity, and duration of maltreatment or institutional rearing have been shown to be significantly associated with a number of critical changes. A major goal of future work will be to clarify inconsistencies across studies.

Taking into account the ever-growing understanding of normative brain development, it is essential that timing of adverse experiences be considered in future work. To illustrate this point, we will discuss what is known on normative developmental of limbic regions, especially given that a large portion of the heterogeneity in findings pertains to these structures. There is growing evidence that the amygdala and hippocampus develop in a non-linear manner in humans (Ostby et al, 2009; Goddings et al, 2014). Hippocampus development is known to lag behind that of the amygdala (Payne et al, 2010). The amygdala is highly developed by the eighth month of gestation (Ulfig et al, 2003). However, it has been shown to increase in size across development in a sex-dependent manner, with females showing earlier maturation than males (Ostby et al, 2009; Goddings et al, 2014). Hippocampal growth rates are shown to be maximal during prenatal and early postnatal points of development, with minimal growth occurring between birth and 2 years of age, and more substantial, steady increases occurring from age 4 into adulthood (Pfluger et al, 1999; Gogtay et al, 2006; Knickmeyer et al, 2008; Jabes and Nelson, 
2015, ahead of print). Subregions of the hippocampus appear to develop at different rates and in different directions; while anterior portions of the hippocampus decrease across development, posterior portions have been shown to increase (Gogtay et al, 2006). Based on these unique and non-linear developmental trajectories of the hippocampus and the amygdala, the timing of the adverse exposure, involving both the age of onset and duration of the exposure, will likely determine the extent of impact.

As we reviewed above, factors related to timing (age of onset, age of removal from adverse setting) have been considered in many studies, but more consistent and careful assessment of these factors will be critical in the future. Beyond the timing of the event, the severity and chronicity of the exposure are also likely determinants of effects and will undoubtedly interact with timing to influence neurodevelopment. More severe and/or chronic exposure during a more sensitive period of development will have greater impact on some regions/circuits than others, when compared with less severe or intermittent exposure during the same interval. So-called 'sleeper effects', in which the impact of an early experience tends not to manifest itself till later in development should also be considered in the context of longitudinal studies. For example, the impact of maltreatment on certain structures (ie, the hippocampus) may not appear until after an 'incubation period' (Lupien et al, 2009) or may interact with prolonged stressors that accumulate across development (Sapolsky, 1996; Sapolsky et al, 2000).

There is also evidence, largely informed from animal studies, that early adverse experiences can lead to increases in certain regions immediately following the exposure (owing to hyperactivation and heightened dendritic arborization); however, these initial increases can be followed by eventual shrinkage (Vyas et al, 2002; McEwen, 2003; Mitra et al, 2005; Vyas et al, 2006; Rosenkranz et al, 2010; Padival et al, 2013a, b). Based on this evidence, it is possible that the consequences on brain development may appear one way in assessments that take place close in time to the adverse experience, and another way when assessed after much time has passed. It is also important to note that there are significant inter-species variations in the impact of early adverse experiences on neurobiological systems (as discussed in Parker et al, 2006). Therefore, caution is also needed when translating findings from animal models to humans.

Adding to this complexity, there are additional factors that complicate findings from human studies. Studies vary in terms of whether individuals meet criteria for psychiatric disorders secondary to maltreatment. Youth who go on to develop psychiatric disorders following early adverse rearing exposures likely differ in important ways from youth who do not develop disorders (ie, in genetic predisposition; inaccess to protective factors). Children reared in maltreating circumstances are also likely to experience a number of ongoing additional stressors, such as poverty, parental psychiatric disorders, and exposure to extreme violence in the family or community, making it difficult to attribute changes to a specific adverse rearing experience that occurs during a particular window of development. However, efforts to carefully assess and quantify these additional factors will likely help in understanding patterns associated with risk.

The type of adverse rearing experience has been discussed as an additional source of variance; the impact of extreme stress because of abuse $v s$ a relative absence of input experienced as part of neglect will challenge the brain in different ways, as suggested in a recent review (McLaughlin et al, 2014). We argue here that additional consideration for the extent to which circumstances disrupt or prevent the normative formation of a selective attachment to a primary caregiver is needed to fully understand patterns of change. The majority of evidence comes from cross-sectional studies, which limit the extent to which causal claims can be made. This is understandable, given inherent challenges associated with longitudinal work. However, prospective longitudinal studies that assess neurodevelopment at multiple stages, starting when children are in early childhood, will undoubtedly help to clarify ambiguities in the field.

In this review, we focused on early adverse experiences involving childhood maltreatment in family settings or experienced in institutional rearing conditions; however, there are additional contexts that place children at risk for non optimal parenting (ie, extreme socioeconomic deprivation or severe parental psychopathology). Very few studies have examined how normative variability in parenting, and associated variability in positive domains of parenting, differentially affects the developing brain, with the exception of a recent few investigations (Rao et al, 2010a; Luby et al, 2012; Euser et al, 2013). Understanding neurodevelopmental differences associated with normative parenting variability may have additional implications for understanding at risk populations.

As we reviewed, there is promising evidence that early intervention can support recovery in the brain. Findings in the two bodies of work reviewed here, involving children exposed to maltreatment in family settings, or psychosocial deprivation in institutional rearing, converge to suggest remediation in neural processes associated cognitive functioning (Bruce et al, 2009; McDermott et al, 2012, 2013). Beyond this domain, there is evidence for broader areas of neural improvement for institutional reared children placed into foster care (Nelson et al, 2014). These studies elucidate the potential for early intervention, involving removal from adverse rearing context and placement into responsive family environments, to normalize brain development and reduce risk for associated cognitive or emotional problems. The randomized design of these studies has also allowed for further understanding on how parenting environments may causally shape neurodevelopment. An important extension of this work will involve examining patterns of neural remediation in other early intervention contexts, such as those involving children who are at risk for maltreatment but remain in their biological families (see for example, Bernard et al, 2014).

As demonstrated by the BEIP, patterns of recovery that result from intervention are also shown to be complex. Some aspects of brain function and structure may be more responsive to environmental enrichment than others. Some 
aspects of neural recovery may be immediate, whereas others take the form of a 'sleeper effect', only becoming apparent later on in life. Finally, the degree to which children show remediation in certain neural processes and associated functioning may depend on the timing of the intervention, and related timing of the sensitive period and corresponding neural process. Despite these nuances, there is clear evidence that early intervention can have a remediating effect on the brain, reducing risk of problematic outcomes.

Our continued efforts to understand how early adverse rearing experiences and early intervention shape the developing brain using developmentally informed research designs will be critical on the road ahead. Such efforts will enable us to provide answers to these highly complex developmental questions, and will maximize the degree to which we can offer preventive and intervention services that support optimal outcomes for vulnerable children and families.

\section{FUNDING AND DISCLOSURE}

The authors declare no conflict of interest.

\section{ACKNOWLEDGMENTS}

Preparation of the manuscript was supported by the NIMH (MH091363) to CA Nelson.

\section{REFERENCES}

Anda RF, Felitti VJ, Bremner JD, Walker JD, Whitfield C, Perry BD et al (2006). The enduring effects of abuse and related adverse experiences in childhood. A convergence of evidence from neurobiology and epidemiology. Eur Arch Psychiatry Clin Neurosci 256: 174-186.

Anderson CM, Teicher MH, Polcari A, Renshaw PF (2002). Abnormal T2 relaxation time in the cerebellar vermis of adults sexually abused in childhood: potential role of the vermis in stress-enhanced risk for drug abuse. Psychoneuroendocrinology 27: 231-244.

Arbel Y, Donchin E (2009). Parsing the componential structure of post-error ERPs: a principal component analysis of ERPs following errors. Psychophysiology 46: 1179-1189.

Arnsten AF (2009). Stress signalling pathways that impair prefrontal cortex structure and function. Nat Rev Neurosci 10: 410-422.

Barry RJ, Johnstone SJ, Clarke AR (2003). A review of electrophysiology in attention-deficit/hyperactivity disorder: II. Event-related potentials. Clin Neurophysiol 114: 184-198.

Bauer PM, Hanson JL, Pierson RK, Davidson RJ, Pollak SD (2009). Cerebellar volume and cognitive functioning in children who experienced early deprivation. Biol Psychiatry 66: 1100-1106.

Behen ME, Muzik O, Saporta AS, Wilson BJ, Pai D, Hua J et al (2009). Abnormal fronto-striatal connectivity in children with histories of early deprivation: a diffusion tensor imaging study. Brain Imaging Behav 3: 292-297.

Benes FM, Turtle M, Khan Y, Farol P (1994). Myelination of a key relay zone in the hippocampal formation occurs in the human brain during childhood, adolescence, and adulthood. Arch Gen Psychiatry 51: 477-484.

Bernard K, Dozier M, Bick J, Gordon MK (2014). Intervening to enhance cortisol regulation among children at risk for neglect: results of a randomized clinical trial. Dev Psychopathol 27: 829-841.

Bick J, Zhu T, Stamoulis C, Fox NA, Zeanah C, Nelson CA (2015). Effect of early institutionalization and foster care on long-term white matter development: a randomized clinical trial. JAMA Pediatr 169: 211-219.

Bogdan R, Williamson DE, Hariri AR (2012). Mineralocorticoid receptor Iso/Nal (rs5522) genotype moderates the association between previous childhood emotional neglect and amygdala reactivity. A J Psychiatry 169: 515-522.

Boksa P (2010). Effects of prenatal infection on brain development and behavior: a review of findings from animal models. Brain Behav Immun 24: 881-897.
Bos KJ, Fox N, Zeanah CH, Nelson CA (2009). Effects of early psychosocial deprivation on the development of memory and executive function. Front Behav Neurosci 3: 16.

Botvinick MM, Cohen JD, Carter CS (2004). Conflict monitoring and anterior cingulate cortex: an update. Trends Cogn Sci 8: 539-546.

Bourgeois JP, Goldman-Rakic PS, Rakic P (1994). Synaptogenesis in the prefrontal cortex of rhesus monkeys. Cereb Cortex 4: 78-96.

Brody BA, Kinney HC, Kloman AS, Gilles FH (1987). Sequence of central nervous system myelination in human infancy. I. An autopsy study of myelination. J Neuropathol Exp Neurol 46: 283-301.

Bruce J, Fisher PA, Graham AM, Moore WE, Peake SJ, Mannering AM (2013). Patterns of brain activation in foster children and nonmaltreated children during an inhibitory control task. Dev Psychopathol 25: 931-941.

Bruce J, McDermott JM, Fisher PA, Fox NA (2009). Using behavioral and electrophysiological measures to assess the effects of a preventive intervention: a preliminary study with preschool-aged foster children. Prevention Science 10: 129-140.

Bush G, Luu P, Posner Ml (2000). Cognitive and emotional influences in anterior cingulate cortex. Trends Cogn Sci 4: 215-222.

Carrion VG, Garrett A, Menon V, Weems CF, Reiss AL (2008). Posttraumatic stress symptoms and brain function during a response-inhibition task: an fMRI study in youth. Depress Anxiety 25: 514-526.

Carrion VG, Haas BW, Garrett A, Song S, Reiss AL (2010). Reduced hippocampal activity in youth with posttraumatic stress symptoms: an fMRI study. $J$ Pediatr Psychol 35: 559-569.

Carrion VG, Weems CF, Eliez S, Patwardhan A, Brown W, Ray RD et al (2001). Attenuation of frontal asymmetry in pediatric posttraumatic stress disorder. Biol Psychiatry 50: 943-951.

Carrion VG, Weems CF, Reiss AL (2007). Stress predicts brain changes in children: a pilot longitudinal study on youth stress, posttraumatic stress disorder, and the hippocampus. Pediatrics 119: 509-516.

Carrion VG, Weems CF, Watson C, Eliez S, Menon V, Reiss AL (2009). Converging evidence for abnormalities of the prefrontal cortex and evaluation of midsagittal structures in pediatric posttraumatic stress disorder: an MRI study. Psychiatry Res 172: 226-234.

Chabot RJ, di Michele F, Prichep L (2005). The role of quantitative electroencephalography in child and adolescent psychiatric disorders. Child Adolesc Psychiatr Clin N Am 14: 21-53 v-vi.

Chugani HT, Behen ME, Muzik O, Juhasz C, Nagy F, Chugani DC (2001). Local brain functional activity following early deprivation: a study of postinstitutionalized Romanian orphans. Neuroimage 14: 1290-1301.

Cicchetti D, Curtis WJ (2005). An event-related potential study of the processing of affective facial expressions in young children who experienced maltreatment during the first year of life. Dev Psychopathol 17: 641-677.

Cohen NJ, Lojkasek M, Zadeh ZY, Pugliese M, Kiefer H (2008). Children adopted from China: a prospective study of their growth and development. J Child Psychol Psychiatry 49: 458-468.

Coles MG, Scheffers MK, Holroyd CB (2001). Why is there an ERN/Ne on correct trials? Response representations, stimulus-related components, and the theory of error-processing. Biol Psychol 56: 173-189.

Colvert E, Rutter M, Beckett C, Castle J, Groothues C, Hawkins A et al (2008b). Emotional difficulties in early adolescence following severe early deprivation: findings from the English and Romanian adoptees study. Dev Psychopathol 20: 547-567.

Colvert E, Rutter M, Kreppner J, Beckett C, Castle J, Groothues C et al (2008a). Do theory of mind and executive function deficits underlie the adverse outcomes associated with profound early deprivation?: findings from the English and Romanian adoptees study. J Abnorm Child Psychol 36: 1057-1068.

Committee on the Rights of the Child, United Nation's Children's Fund (2004). Children without parental care. (37th Session Decision). Office of the United Nations High Commissioner for Human Rights.

Curtis WJ, Cicchetti D (2011). Affective facial expression processing in young children who have experienced maltreatment during the first year of life: An event-related potential study. Development and Psychopathology 23: 373-395.

Curtis WJ, Cicchetti D (2013). Affective Facial Expression Processing in 15-MonthOld Infants Who Have Experienced Maltreatment An Event-Related Potential Study. Child maltreatment 18: 140-154.

da Silva Ferreira GC, Crippa JA, de Lima Osorio F (2014). Facial emotion processing and recognition among maltreated children: a systematic literature review. Front Psychol 5: 1460.

Davidson RJ (1992). Emotion and affective style: hemispheric substrates. Psychological Science 3: 39-43.

Davidson RJ (1993). Cerebral asymmetry and emotion: conceptual and methodological considerations. Cogn Emot 7: 115-138. 
Davidson RJ, Ekman P, Saron CD, Senulis JA, Friesen WV (1990). Approachwithdrawal and cerebral asymmetry: Emotional expression and brain physiology. J Pers Soc Psychol 58: 330-341.

Davidson RJ, Fox NA (1982). Asymmetrical brain activity discriminates between positive and negative affective stimuli in human infants. Science 218: 1235-1237.

De Bellis MD, Hall J, Boring AM, Frustaci K, Moritz G (2001). A pilot longitudinal study of hippocampal volumes in pediatric maltreatment-related posttraumatic stress disorder. Biol Psychiatry 50: 305-309.

De Bellis MD, Hooper SR (2012). Neural substrates for processing task-irrelevant emotional distracters in maltreated adolescents with depressive disorders: a pilot study. J Trauma Stress 25: 198-202.

De Bellis MD, Hooper SR, Spratt EG, Woolley DP (2009). Neuropsychological findings in childhood neglect and their relationships to pediatric PTSD. J Int Neuropsychol Soc 15: 868-878.

De Bellis MD, Keshavan MS, Clark DB, Casey BJ, Giedd JN, Boring AM et al (1999). A.E. Bennett Research Award. Developmental traumatology. Part II: brain development. Biol Psychiatry 45: 1271-1284.

De Bellis MD, Keshavan MS, Shifflett H, lyengar S, Beers SR, Hall J et al (2002). Brain structures in pediatric maltreatment-related posttraumatic stress disorder: a sociodemographically matched study. Biol Psychiatry 52: 1066-1078.

De Bellis MD, Kuchibhatla M (2006). Cerebellar volumes in pediatric maltreatmentrelated posttraumatic stress disorder. Biol Psychiatry 60: 697-703.

De Brito SA, Viding E, Sebastian CL, Kelly PA, Mechelli A, Maris H et al (2013). Reduced orbitofrontal and temporal grey matter in a community sample of maltreated children. J Child Psychol Psychiatry 54: 105-112.

Dillon DG, Holmes AJ, Birk JL, Brooks N, Lyons-Ruth K, Pizzagalli DA (2009). Childhood adversity is associated with left basal ganglia dysfunction during reward anticipation in adulthood. Biol Psychiatry 66: 206-213.

Edmiston EE, Wang F, Mazure CM, Guiney J, Sinha R, Mayes LC et al (2011). Corticostriatal-limbic gray matter morphology in adolescents with self-reported exposure to childhood maltreatment. Arch Pediatr Adolesc Med 165: 1069-1077.

Eluvathingal TJ, Chugani HT, Behen ME, Juhasz C, Muzik O, Maqbool M et al (2006). Abnormal brain connectivity in children after early severe socioemotional deprivation: a diffusion tensor imaging study. Pediatrics 117: 2093-2100.

Euser AS, Evans BE, Greaves-Lord K, Huizink AC, Franken IH (2013). Parental rearing behavior prospectively predicts adolescents' risky decision-making and feedback-related electrical brain activity. Dev Sci 16: 409-427.

Fisher PA, Ellis BH, Chamberlain P (1999). Early intervention foster care: a model for preventing risk in young children who have been maltreated. Children's Services Social Policy Res Practice 2: 159-182.

Fox NA (1991). If it's not left, it's right. Am Psychol 46: 863-872.

Fox SE, Levitt P, Nelson CA (2010). How the timing and quality of early experiences influence the development of brain architecture. Child Dev 81: 28-40.

Fries AB, Pollak SD (2004). Emotion understanding in postinstitutionalized Eastern European children. Dev Psychopathol 16: 355-369.

Fuster JM (2001). The prefrontal cortex-an update: time is of the essence. Neuron 30: 319-333.

Gee DG, Gabard-Durnam LJ, Flannery J, Goff B, Humphreys KL, Telzer EH et al (2013). Early developmental emergence of human amygdala-prefrontal connectivity after maternal deprivation. Proc Natl Acad Sci USA 110: 15638-15643.

Giedd JN, Schmitt JE, Neale MC (2007). Structural brain magnetic resonance imaging of pediatric twins. Hum Brain Mapp 28: 474-481.

Goddings AL, Mills KL, Clasen LS, Giedd JN, Viner RM, Blakemore SJ (2014). The influence of puberty on subcortical brain development. Neuroimage 88: 242-251.

Gogtay N, Nugent TF 3rd, Herman DH, Ordonez A, Greenstein D, Hayashi KM et al (2006). Dynamic mapping of normal human hippocampal development. Hippocampus 16: 664-672.

Govindan RM, Behen ME, Helder E, Makki MI, Chugani HT (2010). Altered water diffusivity in cortical association tracts in children with early deprivation identified with tract-based spatial statistics (TBSS). Cereb Cortex 20: 561-569.

Graham AM, Fisher PA, Pfeifer JH (2013). What sleeping babies hear: a functional MRI study of interparental conflict and infants' emotion processing. Psychol Sci 24: 782-789.

Greenough WT, Black JE, Wallace CS (1987). Experience and brain development Child Dev 58: 539-559.

Hanson JL, Adluru N, Chung MK, Alexander AL, Davidson RJ, Pollak SD (2013). Early neglect is associated with alterations in white matter integrity and cognitive functioning. Child Dev 84: 1566-1578

Hanson JL, Chung MK, Avants BB, Shirtcliff EA, Gee JC, Davidson RJ et al (2010). Early stress is associated with alterations in the orbitofrontal cortex: a tensorbased morphometry investigation of brain structure and behavioral risk. J Neurosci 30: 7466-7472.

Hanson JL, Nacewicz BM, Sutterer MJ, Cayo AA, Schaefer SM, Rudolph KD et al (2014). Behavioral problems after early life stress: contributions of the hippocampus and amygdala. Biol Psychiatry 77: 314-323.
Hart H, Rubia K (2012). Neuroimaging of child abuse: a critical review. Front Hum Neurosci 6: 52

Herringa RJ, Birn RM, Ruttle PL, Burghy CA, Stodola DE, Davidson RJ et al (2013). Childhood maltreatment is associated with altered fear circuitry and increased internalizing symptoms by late adolescence. Proc Natl Acad Sci USA 110 19119-19124.

Herrmann MJ, Rommler J, Ehlis AC, Heidrich A, Fallgatter AJ (2004). Source localization (LORETA) of the error-related-negativity (ERN/Ne) and positivity (Pe). Brain Res Cogn Brain Res 20: 294-299.

Hodel AS, Hunt RH, Cowell RA, Van Den Heuvel SE, Gunnar MR, Thomas KM (2015). Duration of early adversity and structural brain development in postinstitutionalized adolescents. Neuroimage 105: 112-119.

Huang H, Gundapuneedi T, Rao U (2012). White matter disruptions in adolescents exposed to childhood maltreatment and vulnerability to psychopathology. Neuropsychopharmacology 37: 2693-2701.

Hughes G, Yeung N (2011). Dissociable correlates of response conflict and error awareness in error-related brain activity. Neuropsychologia 49: 405-415.

Huttenlocher PR, Dabholkar AS (1997). Regional differences in synaptogenesis in human cerebral cortex. J Comp Neurol 387: 167-178.

Huttenlocher PR, de Courten C, Garey LJ, Van der Loos H (1982). Synaptogenesis in human visual cortex-evidence for synapse elimination during normal development. Neurosci Lett 33: 247-252.

Ito $\mathrm{Y}$, Teicher MH, Glod CA, Ackerman E (1998). Preliminary evidence for aberrant cortical development in abused children: a quantitative EEG study. J Neuropsychiatry Clin Neurosci 10: 298-307.

Jabes A, Nelson CA. 20 years after "The ontogeny of human memory: a cognitive neuroscience perspective". Where are we?. Int J Behav Dev 2015. (ahead of print).

Jackowski AP, Douglas-Palumberi H, Jackowski M, Win L, Schultz RT, Staib LW et al (2008). Corpus callosum in maltreated children with posttraumatic stress disorder: a diffusion tensor imaging study. Psychiatry Res 162: 256-261.

Johnson DE, Guthrie D, Smyke AT, Koga SF, Fox NA, Zeanah CH et al (2010). Growth and associations between auxology, caregiving environment, and cognition in socially deprived Romanian children randomized to foster vs ongoing institutional care. Arch Pediatr Adolesc Med 164: 507-516.

Kelly PA (2013). Cortical thickness, surface area, and gyrification abnormalities in children exposed to maltreatment: neural markers of vulnerability?. Biological Psychiatry 74: 845-852.

Kim SG, Ugurbil K, Strick PL (1994). Activation of a cerebellar output nucleus during cognitive processing. Science 265: 949-951.

Knickmeyer RC, Gouttard S, Kang C, Evans D, Wilber K, Smith JK et al (2008). A structural MRI study of human brain development from birth to 2 years. J Neurosci 28: 12176-12182.

Kreppner JM, O'Connor TG, Rutter M (2001). Can inattention/overactivity be an institutional deprivation syndrome? J Abnorm Child Psychol 29: 513-528.

Kumar A, Behen ME, Singsoonsud P, Veenstra AL, Wolfe-Christensen C, Helder E et al (2013). Microstructural Abnormalities in Language and Limbic Pathways in Orphanage-Reared Children A Diffusion Tensor Imaging Study. Journal of child neurology, 0883073812474098.

Kumar A, Behen ME, Singsoonsud P, Veenstra AL, Wolfe-Christensen C, Helder E et al (2014). Microstructural abnormalities in language and limbic pathways in orphanage-reared children: a diffusion tensor imaging study. J Child Neurol 318-325

LaMantia AS, Rakic P (1994). Axon overproduction and elimination in the anterior commissure of the developing rhesus monkey. J Comp Neurol 340: 328-336.

Leiner HC, Leiner AL, Dow RS (1991). The human cerebro-cerebellar system: its computing, cognitive, and language skills. Behav Brain Res 44: 113-128.

Levy R, Goldman-Rakic PS (2000). Segregation of working memory functions within the dorsolateral prefrontal cortex. Exp Brain Res 133: 23-32.

Liao M, Yang F, Zhang Y, He Z, Song M, Jiang T et al (2013). Childhood maltreatment is associated with larger left thalamic gray matter volume in adolescents with generalized anxiety disorder. PLoS One 8: e71898.

Lim L, Hart H, Mehta MA, Simmons A, Mirza K, Rubia K (2015). Neural correlates of error processing in young people with a history of severe childhood abuse: an fMRI study. A J Psychiatry appiajp201514081042 892: 892-900.

Loman MM, Wiik KL, Frenn KA, Pollak SD, Gunnar MR (2009). Postinstitutionalized children's development: growth, cognitive, and language outcomes. J Dev Behav Pediatr 30: 426-434.

Luby JL, Barch DM, Belden A, Gaffrey MS, Tillman R, Babb C et al (2012). Maternal support in early childhood predicts larger hippocampal volumes at school age. Proc Natl Acad Sci USA 109: 2854-2859

Lupien SJ, McEwen BS, Gunnar MR, Heim C (2009). Effects of stress throughout the lifespan on the brain, behaviour and cognition. Nat Rev Neurosci 10: 434-445.

Lupien SJ, Parent S, Evans AC, Tremblay RE, Zelazo PD, Corbo V et al (2011). Larger amygdala but no change in hippocampal volume in 10-year-old children 
exposed to maternal depressive symptomatology since birth. Proc Natl $\mathrm{Acad} \mathrm{Scl}$ USA 108: 14324-14329.

Lyons-Ruth K (2008). Contributions of the mother-infant relationship to dissociative, borderline, and conduct symptoms in young adulthood. Infant Ment Health J 29: 203-218.

MacKenzie MJ, Gearing RE, Schwalbe CS, Ibrahim RW, Brewer KB, Al-Sharaihah R (2014). Child mental health in Jordanian orphanages: effect of placement change on behavior and caregiving. BMC Pediatr 14: 316

MacLean K (2003). The impact of institutionalization on child development. Dev Psychopathol 15: 853-884.

Magill CR, Ashley GM, Freeman KH (2013). Water, plants, and early human habitats in eastern Africa. Proc Natl Acad Sci USA 110: 1175-1180.

Maheu FS, Dozier M, Guyer AE, Mandell D, Peloso E, Poeth Ket al (2010). A preliminary study of medial temporal lobe function in youths with a history of caregiver deprivation and emotional neglect. Cogn Affect Behav Neurosci 10: 34-49.

Marshall PJ, Fox NA (2004). A comparison of the electroencephalogram between institutionalized and community children in Romania. J Cogn Neurosci 16: 1327-1338.

Marshall PJ, Reeb BC, Fox NA, Nelson CA, Zeanah CH (2008). Effects of early intervention on EEG power and coherence in previously institutionalized children in Romania. Dev Psychopathol 20: 861-880.

McCrory E, De Brito SA, Viding E (2011a). The impact of childhood maltreatment: a review of neurobiological and genetic factors. Front Psychiatry 2: 48

McCrory EJ, De Brito SA, Sebastian CL, Mechelli A, Bird G, Kelly PA et al (2011b). Heightened neural reactivity to threat in child victims of family violence. Curr Biol 21: R947-R948.

McDermott JM, Troller-Renfree S, Vanderwert R, Nelson CA, Zeanah CH, Fox NA (2013). Psychosocial deprivation, executive functions, and the emergence of socio-emotional behavior problems. Front Hum Neurosci 7: 167.

McDermott JM, Westerlund A, Zeanah CH, Nelson CA, Fox NA (2012). Early adversity and neural correlates of executive function: implications for academic adjustment. Dev Cogn Neurosci 2(Suppl 1): S59-S66.

McEwen BS (2003). Mood disorders and allostatic load. Biol Psychiatry 54: 200-207.

McLaughlin KA, Fox NA, Zeanah CH, Nelson CA (2011). Adverse rearing environments and neural development in children: the development of frontal electroencephalogram asymmetry. Biol Psychiatry 70: 1008-1015.

McLaughlin KA, Sheridan MA, Lambert HK (2014). Childhood adversity and neural development: deprivation and threat as distinct dimensions of early experience. Neurosci Biobehav Rev 47: 578-591.

McLaughlin KA, Sheridan MA, Winter W, Fox NA, Zeanah CH, Nelson CA (2013). Widespread reductions in cortical thickness following severe early-life deprivation: a neurodevelopmental pathway to attention-deficit/hyperactivity disorder. Biol Psychiatry 76: 629-638.

Mehta MA, Golembo NI, Nosarti C, Colvert E, Mota A, Williams SC et al (2009b). Amygdala, hippocampal and corpus callosum size following severe early institutional deprivation: the English and Romanian Adoptees study pilot. J Child Psychol Psychiatry 50: 943-951.

Mehta MA, Gore-Langton E, Golembo N, Colvert E, Williams SCR, Sonuga-Barke E (2009a). Hyporesponsive reward anticipation in the basal ganglia following severe institutional deprivation early in life. J Cogn Neurosci 22: 2316-2325.

Meyer A, Proudfit GH, Bufferd SJ, Kujawa AJ, Laptook RS, Torpey DC et al (2014). Self-reported and observed punitive parenting prospectively predicts increased error-related brain activity in six-year-old children. J Abnorm Child Psychol 43: $821-829$.

Miller EK, Cohen JD (2001). An integrative theory of prefrontal cortex function. Annu Rev Neurosci 24: 167-202.

Miskovic V, Schmidt LA, Georgiades K, Boyle M, MacMillan HL (2009). Stability of resting frontal electroencephalogram (EEG) asymmetry and cardiac vagal tone in adolescent females exposed to child maltreatment. Dev Psychobiol 51: 474-487.

Miskovic V, Schmidt LA, Georgiades K, Boyle M, Macmillan HL (2010). Adolescent females exposed to child maltreatment exhibit atypical EEG coherence and psychiatric impairment: linking early adversity, the brain, and psychopathology. Dev Psychopathol 22: 419-432.

Mitra R, Jadhav S, McEwen BS, Vyas A, Chattarji S (2005). Stress duration modulates the spatiotemporal patterns of spine formation in the basolateral amygdala. Proc Natl Acad Sci USA 102: 9371-9376.

Morgane PJ, Austin-LaFrance R, Bronzino J, Tonkiss J, Diaz-Cintra S, Cintra L et al (1993). Prenatal malnutrition and development of the brain. Neurosci Biobehav Rev 17: 91-128.

Moulson MC, Fox NA, Zeanah CH, Nelson CA (2009a). Early adverse experiences and the neurobiology of facial emotion processing. Dev Psychol 45: 17-30.

Moulson MC, Westerlund A, Fox NA, Zeanah CH, Nelson CA (2009b). The effects of early experience on face recognition: an event-related potential study of institutionalized children in Romania Child Dev 80: 1039-1056.
Mueller SC, Maheu FS, Dozier M, Peloso E, Mandell D, Leibenluft E et al (2010). Early-life stress is associated with impairment in cognitive control in adolescence: an fMRI study. Neuropsychologia 48: 3037-3044.

Murray EA (2007). The amygdala, reward and emotion. Trends Cogn Sci 11: 489-497.

Nelson C, Jeste S (2009). Neurobiological perspectives on developmental psychopathologyIn: Rutter's Child and Adolescent Psychiatry. Blackwell Publishing. Oxford, UK. pp 145-159.

Nelson CA, Fox NA, Zeanah CH (2014). Romania's abandoned children: deprivation, brain development and the struggle for recoveryHarvard University Press: Cambridge, MA.

Nelson CA, Westerlund A, McDermott JM, Zeanah CH, Fox NA (2013). Emotion recognition following early psychosocial deprivation. Dev Psychopathol 25: 517-525

Nelson CA, Zeanah CH, Fox NA, Marshall PJ, Smyke AT, Guthrie D (2007). Cognitive recovery in socially deprived young children: the Bucharest Early Intervention Project. Science 318: 1937-1940.

Nieuwenhuis S, Ridderinkhof KR, Blom J, Band GP, Kok A (2001). Error-related brain potentials are differentially related to awareness of response errors: evidence from an antisaccade task. Psychophysiology 38: 752-760.

Ochsner KN, Bunge SA, Gross JJ, Gabrieli JD (2002). Rethinking feelings: an FMRI study of the cognitive regulation of emotion. J Cogn Neurosci 14: 1215-1229.

Ochsner KN, Gross JJ (2005). The cognitive control of emotion. Trends Cogn Sci 9: 242-249.

Olsavsky AK, Telzer EH, Shapiro M, Humphreys KL, Flannery J, Goff B et al (2013). Indiscriminate amygdala response to mothers and strangers after early maternal deprivation. Biol Psychiatry 74: 853-860.

Ostby Y, Tamnes CK, Fjell AM, Westlye LT, Due-Tonnessen P, Walhovd KB (2009). Heterogeneity in subcortical brain development: a structural magnetic resonance imaging study of brain maturation from 8 to 30 years. J Neurosci 29: 11772-11782.

Ouyang L, Fang X, Mercy J, Perou R, Grosse SD (2008). Attention-deficit/ hyperactivity disorder symptoms and child maltreatment: a populationbased study. J Pediatr 153: 851-856.

Padival M, Quinette D, Rosenkranz JA (2013a). Effects of repeated stress on excitatory drive of basal amygdala neurons in vivo. Neuropsychopharmacology 38: 1748-1762.

Padival MA, Blume SR, Rosenkranz JA (2013b). Repeated restraint stress exerts different impact on structure of neurons in the lateral and basal nuclei of the amygdala. Neuroscience 246: 230-242.

Parker KJ, Buckmaster CL, Sundlass K, Schatzberg AF, Lyons DM (2006). Maternal mediation, stress inoculation, and the development of neuroendocrine stress resistance in primates. Proc Natl Acad Sci USA 103: 3000-3005.

Payne C, Machado CJ, Bliwise NG, Bachevalier J (2010). Maturation of the hippocampal formation and amygdala in Macaca mulatta: a volumetric magnetic resonance imaging study. Hippocampus 20: 922-935.

Pechtel P, Pizzagalli DA (2011). Effects of early life stress on cognitive and affective function: an integrated review of human literature. Psychopharmacology (Berl) 214: $55-70$.

Petanjek Z, Judas M, Kostovic I, Uylings HB (2008). Lifespan alterations of basal dendritic trees of pyramidal neurons in the human prefrontal cortex: a layerspecific pattern. Cereb Cortex 18: 915-929.

Pfluger T, Weil S, Weis S, Vollmar C, Heiss D, Egger J et al (1999). Normative volumetric data of the developing hippocampus in children based on magnetic resonance imaging. Epilepsia 40: 414-423.

Phelps EA (2004). Human emotion and memory: interactions of the amygdala and hippocampal complex. Curr Opin Neurobiol 14: 198-202.

Pollak SD, Cicchetti D, Klorman R, Brumaghim JT (1997). Cognitive Brain Event-Related Potentials and Emotion Processing in Maltreated. Child Development 68: 773-787.

Pollak SD, Cicchetti D, Hornung K, Reed A (2000). Recognizing emotion in faces: developmental effects of child abuse and neglect. Dev Psychol 36: 679-688.

Pollak SD, Klorman R, Thatcher JE, Cicchetti D (2001). P3b reflects maltreated children's reactions to facial displays of emotion. Psychophysiology 38: 267-274.

Pollak SD, Kistler DJ (2002). Early experience is associated with the development of categorical representations for facial expressions of emotion. Proc Natl Acad Sci USA 99: 9072-9076.

Pollak SD, Nelson CA, Schlaak MF, Roeber BJ, Wewerka SS, Wiik KL et al (2010). Neurodevelopmental effects of early deprivation in postinstitutionalized children. Child Dev 81: 224-236

Pollak SD, Sinha P (2002). Effects of early experience on children's recognition of facial displays of emotion. Dev Psychol 38: 784-791.

Pollak SD, Tolley-Schell SA (2003). Selective attention to facial emotion in physically abused children. J Abnorm Psychol 112: 323-338.

Rao H, Betancourt L, Giannetta JM, Brodsky NL, Korczykowski M, Avants BB et al (2010a). Early parental care is important for hippocampal maturation: evidence from brain morphology in humans. Neuroimage 49: 1144-1150. 
Rao U, Chen LA, Bidesi AS, Shad MU, Thomas MA, Hammen CL (2010b). Hippocampal changes associated with early-life adversity and vulnerability to depression. Biol Psychiatry 67: 357-364.

Richert KA, Carrion VG, Karchemskiy A, Reiss AL (2006). Regional differences of the prefrontal cortex in pediatric PTSD: an MRI study. Depress Anxiety 23 17-25.

Roger C, Benar CG, Vidal F, Hasbroucq T, Burle B (2010). Rostral cingulate zone and correct response monitoring: ICA and source localization evidences for the unicity of correct- and error-negativities. Neuroimage 51: 391-403.

Rosenkranz JA, Venheim ER, Padival M (2010). Chronic stress causes amygdala hyperexcitability in rodents. Biol Psychiatry 67: 1128-1136.

Rutter M, Kreppner JM, O'Connor TGEnglish Romanian Adoptees (ERA) (2001). Specificity and heterogeneity in children's responses to profound institutional privation. Br J Psychiatry 17: 97-103.

Rutter M, O'Connor TG (2004). Are there biological programming effects for psychological development? Findings from a study of Romanian adoptees. Dev Psychol 40: 81-94.

Sapolsky RM (1996). Stress, glucocorticoids, and damage to the nervous system: the current state of confusion. Stress 1: 1-19.

Sapolsky RM, Romero LM, Munck AU (2000). How do glucocorticoids influence stress responses? Integrating permissive, suppressive, stimulatory, and preparative actions. Endocr Rev 21: 55-89.

Schoenbaum G, Saddoris MP, Stalnaker TA (2007). Reconciling the roles of orbitofrontal cortex in reversal learning and the encoding of outcome expectancies. Ann N Y Acad Sci 1121: 320-335.

Schultz W, Tremblay L, Hollerman JR (2000). Reward processing in primate orbitofrontal cortex and basal ganglia. Cereb Cortex 10: 272-284.

Shackman JE, Shackman AJ, Pollak SD (2007). Physical abuse amplifies attention to threat and increases anxiety in children. Emotion 7: 838.

Shackman JE, Pollak SD (2014). Impact of physical maltreatment on the regulation of negative affect and aggression. Dev Psychopathol 26 1021-1033.

Sheridan MA, Fox NA, Zeanah CH, McLaughlin KA, Nelson CA 3rd (2012). Variation in neural development as a result of exposure to institutionalization early in childhood. Proc Natl Acad Sci USA 109: 12927-12932.

Slopen N, McLaughlin KA, Fox NA, Zeanah CH, Nelson CA (2012). Alterations in neural processing and psychopathology in children raised in institutions. Arch Gen Psychiatry 69: 1022-1030.

Spitz RA (1945). Hospitalism; an inquiry into the genesis of psychiatric conditions in early childhood. Psychoanal Study Child 1: 53-74.

Spratt EG, Friedenberg SL, Swenson CC, Larosa A, De Bellis MD, Macias MM et al (2012). The effects of early neglect on cognitive, language, and behavioral functioning in childhood. Psychology (Irvine) 3: 175-182.

Stevens SE, Sonuga-Barke EJ, Kreppner JM, Beckett C, Castle J, Colvert E et al (2008). Inattention/overactivity following early severe institutional deprivation: presentation and associations in early adolescence. J Abnorm Child Psychol 36: 385-398.

Tanaka SC, Doya K, Okada G, Ueda K, Okamoto Y, Yamawaki S (2004). Prediction of immediate and future rewards differentially recruits cortico-basal ganglia loops. Nat Neurosci 7: 887-893.

Teicher MH, Dumont NL, Ito Y, Vaituzis C, Giedd JN, Andersen SL (2004). Childhood neglect is associated with reduced corpus callosum area. Biol Psychiatry 56: 80-85.
Thatcher RW, Krause PJ, Hrybyk M (1986). Cortico-cortical associations and EEG coherence: a two-compartmental model. Electroencephalogr Clin Neurophysio 64: $123-143$

Thompson BL, Levitt P, Stanwood GD (2009). Prenatal exposure to drugs: effects on brain development and implications for policy and education. Nat Rev Neurosci 10: 303-312.

Tottenham N, Hare TA, Millner A, Gilhooly T, Zevin JD, Casey BJ (2011). Elevated amygdala response to faces following early deprivation. Dev Sci 14: 190-204.

Tottenham N, Hare TA, Quinn BT, McCarry TW, Nurse M, Gilhooly T et al (2010). Prolonged institutional rearing is associated with atypically large amygdala volume and difficulties in emotion regulation. Dev Science 13: 46-61.

Tottenham N (2014). The importance of early experiences for neuro-affective development. The Neurobiology of Childhood. Springer Berlin Heidelberg, 109-129.

Tupler LA, De Bellis MD (2006). Segmented hippocampal volume in children and adolescents with posttraumatic stress disorder. Biol Psychiatry 59: 523-529.

Ulfig N, Setzer M, Bohl J (2003). Ontogeny of the human amygdala. Ann N Y Acad Sci 985: 22-33.

UNICEF (2007). Children without parental care.

van $\mathrm{IMH}$, Palacios J, Sonuga-Barke EJ, Gunnar MR, Vorria P, McCall RB et al (2011). Children in institutional care: delayed development and resilience. Monogr Soc Res Child Dev 76: 8-30.

van den Dries L, Juffer F, van ljzendoorn MH, Bakermans-Kranenburg MJ (2010). Infants' physical and cognitive development after international adoption from foster care or institutions in China. J Dev Behav Pediatr 31: 144-150.

Van Veen V, Carter CS (2002). The timing of action-monitoring processes in the anterior cingulate cortex. J Cogn Neurosci 14: 593-602.

Vanderwert RE, Marshall PJ, Nelson CA 3rd, Zeanah CH, Fox NA (2010). Timing of intervention affects brain electrical activity in children exposed to severe psychosocial neglect. PLoS One 5: e11415.

Vyas A, Jadhav S, Chattarji S (2006). Prolonged behavioral stress enhances synaptic connectivity in the basolateral amygdala. Neuroscience 143: 387-393.

Vyas A, Mitra R, Shankaranarayana Rao BS, Chattarji S (2002). Chronic stress induces contrasting patterns of dendritic remodeling in hippocampal and amygdaloid neurons. J Neurosci 22: 6810-6818.

White MG, Bogdan R, Fisher PM, Munoz KE, Williamson DE, Hariri AR (2012). FKBP5 and emotional neglect interact to predict individual differences in amygdala reactivity. Genes Brain Behav 11: 869-878.

Whittle S, Dennison M, Vijayakumar N, Simmons JG, Yucel M, Lubman DI et al (2013). Childhood maltreatment and psychopathology affect brain development during adolescence. J Am Acad Child Adolesc Psychiatry 52: 940-952 e941.

Woon FL, Hedges DW (2008). Hippocampal and amygdala volumes in children and adults with childhood maltreatment-related posttraumatic stress disorder: a metaanalysis. Hippocampus 18: 729-736.

Yakovlev PI, Lecours AR (1967). The myelogenetic cycles of regional maturation of the brain. Regional Dev Brain Early Life 3-70.

Zeanah CH, Egger HL, Smyke AT, Nelson CA, Fox NA, Marshall PJ et al (2009). Institutional rearing and psychiatric disorders in Romanian preschool children. Am J Psychiatry 166: 777-785.

Zeanah CH, Nelson CA, Fox NA, Smyke AT, Marshall P, Parker SW et al (2003). Designing research to study the effects of institutionalization on brain and behavioral development: the Bucharest Early Intervention Project. Dev Psychopathol 15: 885-907 